\title{
BLACK AMERICAN STUDENTS WITH AND WITHOUT DISABILITIES: STRESS AND COPING STRATEGIES
}

\author{
Gabriel Asare Sarpong
}

79 Pages

This study examined if perceived level of stress for Black /African American students was exacerbated by their disability status. This study also examined the relationship between Africultural coping, minority stressors (racial minority stress, disability related stress) and perceive stress level. 123 students who identified themselves as Black/African Americans enrolled in two Midwestern universities participated in the online survey of this study $(\mathrm{n}=39$ with disabilities; $\mathrm{n}=84$ with no disabilities). Results showed that Black students with disabilities reported higher level of perceived stress compared to those with no disabilities. Racial minority stressors, and societal barrier component of disability related stressors were positively associated with perceived stress significantly. Africultural coping did not moderate the association between racial minority stressors and perceived stress nor the one between disability-related stressors and perceived stress. This suggests that Africultural coping may not reduce felt stress encountered by racism and ableism. Implications and future research directions were discussed

KEYWORDS: Black American Students, Disability, Stress, Coping Strategies, Minority Stressor 
BLACK AMERICAN STUDENTS WITH AND WITHOUT DISABILITIES:

STRESS AND COPING STRATEGIES

GABRIEL ASARE SARPONG

A Thesis Submitted in Partial

Fulfillment of the Requirements

for the Degree of

\section{MASTER OF SCIENCE}

Department of Psychology

ILLINOIS STATE UNIVERSITY 
(C) 2020 Gabriel Asare Sarpong 


\title{
BLACK AMERICAN STUDENTS WITH AND WITHOUT DISABILITIES: \\ STRESS AND COPING STRATEGIES
}

\author{
GABRIEL ASARE SARPONG
}

COMMITTEE MEMBERS:

Suejung Han, Chair

Gregory Braswell 


\section{ACKNOWLEDGMENTS}

I am dedicating this thesis to my Heavenly Father from whom all my strength comes. It has been by God's grace that I have been able to persevere through each day outside my country Ghana with the faith of knowing that God has already orchestrated success for my life. I would like to also dedicate this research thesis to my father, Mr. John Osei Sarpong, who always encouraged me to keep my eyes on the prize. To my mother, Mrs. Christina Sarpong, thank you for encouraging me to reach any goal I desire for my life. I also dedicate this research to my siblings and family, Dr. Felix Osei-Sarpong, Mavis Sarpong, Harriet Sarpong, Eugenia Sarpong, Denzel Asare-Sarpong and Lady Diana Korankye. Thank you all for believing in me and praying for me to achieve my goals.

I must give a special dedication to Dr. Suejung Han for her unconditional support of my research and her commitment to my success with this research thesis. Dr. Braswell, thank you for your feedback and encouragement which were always welcomed and always appreciated. Dr. Cutting, thank you for your time volunteering as a reader for my thesis. Dr. Michael Stevens, I enjoyed getting to learn from you and your genuineness. Jamie Berry, I cannot thank you enough for being a wonderful human to me in United States as well as a good supervisor words cannot describe. Dr. Alec Testa, I appreciate your encouragement, care and support of me throughout my graduate studies. Dr. Karen Mark, thank you very much for always making time for me.

Lastly, I would like to acknowledge the many psychology professors at Illinois State University that I have had, that have played a role in furthering my education. I thank you all for making my experience at Illinois State University one that I will always cherish. I am extraordinarily thankful for the students who participated in my study as well.

G.A. S. 


\section{CONTENTS}

Page

ACKNOWLEDGMENTS

$\begin{array}{ll}\text { CONTENTS } & \text { ii }\end{array}$

TABLES

FIGURES

CHAPTER I: INTRODUCTION 1

$\begin{array}{ll}\text { Background of the Study } & 1\end{array}$

Statement of the Problem $\quad 3$

$\begin{array}{ll}\text { Present Study and Hypotheses } & 6\end{array}$

$\begin{array}{ll}\text { Hypothesis } 1(\mathrm{H} 1) & 7\end{array}$

$\begin{array}{ll}\text { Hypothesis } 2(\mathrm{H} 2) & 7\end{array}$

Hypothesis $3(\mathrm{H} 3) \quad 8$

Research Question (R 1) 9

Relevance of the Research 9

CHAPTER II: REVIEW OF RELATED LITERATURE 13

$\begin{array}{ll}\text { The Concept of Stress } & 13\end{array}$

$\begin{array}{ll}\text { Perception of Stressors } & 13\end{array}$

$\begin{array}{ll}\text { Stress Response } & 14\end{array}$

$\begin{array}{ll}\text { Minority Stress } & 15\end{array}$

Stress Experienced By Black Americans 16

Stress Experienced by Individuals with Disability 19

Stress Experienced By Racial Minorities with Disabilities 21 
$\begin{array}{lr}\text { Africultural Coping Strategies } & 25\end{array}$

Coping Strategies Used by Individuals Challenged with Disability 26

$\begin{array}{ll}\text { CHAPTER III: METHOD } & 28\end{array}$

$\begin{array}{lr}\text { Population and Sample Procedure } & 28\end{array}$

$\begin{array}{lr}\text { Data Screening } & 28\end{array}$

$\begin{array}{ll}\text { Instrumentation } & 29\end{array}$

$\begin{array}{ll}\text { Perceived Stress Scale (PSS) } & 29\end{array}$

$\begin{array}{ll}\text { Minority Student Stress Scale (MSSS) } & 30\end{array}$

Africultural Coping System Inventory (ACSI) 31

World Health Organization Disability Assessment Schedule 2.0 (WHODAS 2) 32

Disability-Related Stress Scale (DRSS) 33

CHAPTER IV: RESULTS 35

$\begin{array}{ll}\text { Data Analysis } & 35\end{array}$

$\begin{array}{ll}\text { Hypotheses Testing } & 39\end{array}$

Hypothesis $1(\mathrm{H} 1) \quad 39$

Hypothesis $2(\mathrm{H} 2) \quad 39$

$\begin{array}{lr}\text { Hypothesis } 3(\mathrm{H} 3) & 40\end{array}$

$\begin{array}{ll}\text { Supplementary Analyses } & 44\end{array}$

$\begin{array}{ll}\text { Exploratory Question } & 45\end{array}$

Research Question (R1) $\quad 45$

$\begin{array}{ll}\text { CHAPTER V: DISCUSSIONS } & 47\end{array}$

Stress Level Related to the Intersectionality of Black Identity and Disability Status 47 
APPENDIX B: PERCEIVED STRESS SCALE

APPENDIX F: WORLD HEALTH ORGANIZATION DISABILITY ASSESSMENT 


\section{TABLES}

Table

Page

1. Descriptive Statistics of Study Variables among Black Americans with and without Disabilities

2. T-test Results for Equality of Means Comparing Black Americans with and without Disabilities on Level of Perceived Stress Scores

3. Descriptive Statistics and Correlations Between Perceived Stress and Racial Minority Student Stress

4. Descriptive Statistics and Correlations Between Perceived Stress and Disability Related Stress Scale Scores

5. Means, Standard Deviations and Correlation between MSSS And DRSS

6. Moderation Effect of Africultural Coping Strategies on the Relationship between Racial Minority Student Stress and Perceived Stress Level

7. Moderation Effect of Africultural Coping Strategies on the Relationship Between Disability Related Stress and Perceived Stress Level

8. Sample Descriptive Statics and Multiple Analyses of Variance in Africultural Coping between Black American Students with Disabilities and Black American Students without Disabilities 


\section{FIGURES}

Figure

1. The Hypothetical Model for $\mathrm{H} 2$

2. The Hypothetical Model for H3
Page

11

12 


\section{CHAPTER I: INTRODUCTION}

\section{Background of the Study}

Stress in university students is concerning. College life has been reported to be a period of increasing levels of stress among students (Hystad et al., 2009). Moreover, present-day students are reporting higher levels of stress than students have disclosed in past generations (Welle \& Graf, 2011). A national review of the health of college students in the United States ( $N=79,266)$ by the American College Health Association (2014) found students to report stress as the most significant factor impacting their academic performance. Similarly, undergraduates who reported to have encountered stress performed poorly academically (Andrews \& Wilding, 2004; Turner \& Smith, 2015). Stress also has been known to increase the risk of anxiety (Eisenberg et al., 2007) and depression (Dyson \& Renk, 2006), damaging emotional and social adjustment to university (Friedlander et al. 2007). Dusselier et al. (2005) explain further that most of the emotional and physical symptoms common in the student population such as headaches, depression, anxiety, and the inability to cope, could be attributed to stress. Thus, effective coping with stress is pivotal for academic success and psychological well-being among college students.

Students with more advantaged backgrounds (e.g., Whites, able-bodied) may have more resources or usually be situated in a better position to cope with the stressors they encounter at Predominantly White Institutions (PWI's). This, however, may not be the case for those students from disadvantaged groups at PWI's (e.g., racial/ethnic minorities, with a disability). In addition to general college stressors (e.g., academic demands, increased need for autonomy), racial minority students, for example, experience additional stressors such as racial microaggressions and difficulty in adjustment to the majority culture when studying in a Predominantly White 
Institutions (Robothan \& Julian, 2006). Museus and Quaye (2009) assert that people of color are challenged with additional stressors that stem from systematic oppression and prejudice daily that they must continuously overcome. Among racial minorities, Greer and Chwalisz (2007) in their research found that many Black American college students who attend predominately White universities find their minority status to be a unique source of stress for them. Further research by Reid and Smalls (2004) support that Black Americans disproportionately suffer from stress-related conditions compared to their White counterparts.

In addition to racially minoritized status, the stress level of adults with disabilities in the U.S was almost as twice compared to adults without disability (33\% and 18\%, respectively), according to the America Psychological Association (2016) survey on stress in America. The National Center for Educational Statistics (NCES, 2016) research data reveals that during the 2011-2012 school year, the percentage of undergraduate students in degree-granting institutions who reported having a disability was $11.1 \%$. Although there was no gender difference in the disability prevalence, there were some variations across racial and ethnic groups among the undergraduate students. Specifically, $12.2 \%$ of undergraduates who identified as Black Americans reported having a disability, compared to undergraduates from the other ethnic groups who identified themselves with disabilities (i.e., 14.4\% for Native Americans, $11.1 \%$ for Whites, $10.4 \%$ for Hispanics and $8.0 \%$ for Asians).

Although approximately $12 \%$ of U.S. college students with disabilities are Black Americans (NCES, 2016), little research has examined Black American students with disabilities. Most studies on minority stress among Black American college students have not examined the intersectionality with disability status. Intersectionality as an approach acknowledges that multiple identities such as social relations, disabilities, cultures may define 
people's lives (Blick, et al., 2015). Cole (2009) explains that intersectionality invites researchers to focus on the unique experiences of oppressed groups in society while taking into consideration the social and historical context of those groups. Myers (2009) lamented that so much psychological research on minority fails to address within-group differences. Intersectionality between racial minority status and disability is particularly important to examine, as described in the following section.

\section{Statement of the Problem}

Although disability is not a barrier to higher education, a lack of institutional support services and programs can adversely affect the educational experience of students with disabilities. Research by the National Center for Special Education Research (NCSER) reveals that within eight years period, only 34 percent of students with disability graduated from fouryear college programs (NCSER, 2011). Thus, the graduation rate is therefore significantly lower for individuals with disabilities compared to the general student population where 51 percent of them graduated within a period of eight years after they complete high school (Newman et al., 2011). Although Black Americans constitute $12.7 \%$ of the entire United States population (American Community Survey, 2016), the disability rate for Black Americans is 22.2\% (Brault, 2012) which is higher when compared to the other racial groups (17.8\% in Hispanics and $17.4 \%$ in non-Hispanic Whites). So one might reasonably question why the appearance of research on stress experienced by Black Americans university students with disabilities has taken so long considering the fact that a greater percentage of Black/African American university students appear to have a disability?

According to McNeil (1993), Black/African Americans with disabilities are at increased risk of stress and its negative functional outcomes. Previous research by Asbury et al (1991) 
reported Black Americans with disabilities to have lower levels of education when compared to their European American counterparts with disabilities. Black/African American students with disabilities face the double challenge of having to cope with discrimination based on both disability and racial minority status (Esses \& Beaufoy, 1994; McDonald \& Colleagues, 2007). Also, Black/African Americans with disabilities have the added disadvantage of being subjected to greater negative attitudes by the majority in society compared to other minority groups (Blanchett et al., 2005). For instance, although Black/African Americans are usually stereotyped as having lower intelligence (Ancis, Sedlacek, \& Mohr, 2000), the commonly held stereotypes about people with disabilities such as low intelligence may further magnify the stressors experienced by Black American students with disabilities (HHS, 2011). This can make Black American students with invisible disabilities (e.g. anxiety disorder) wary of opening up to either classmates or professors and as a result, they may not receive the assistance they require to succeed.

Black American students with disabilities, therefore, experience what Blanchett, Mumford, and Beachum (2005) describe as "double jeopardy." Also, these students are more likely to face barriers in receiving culturally relevant services as well. Due to cultural mistrust (Whaley, 2001) in the healthcare, mental healthcare, and educational system operated by majority Whites, Black American students may be less likely to seek help or systemic resources (e.g., counseling center services). Research also shows that students with disabilities may feel apprehensive about seeking accommodations due to fear of being perceived as making excuses or weak (Holmes \& River, 1998). Then, Black American students with disabilities may experience double barriers for seeking resources for dealing with their general college stress and also minority stressors caused by their double minority status. Therefore, it is imperative to 
examine perceived stress among Black students with disabilities, and how they cope with such stress.

A significant amount of research corroborates that how an individual perceives stress influences how the person copes with stress (Giancola, Grawitch, \& Borchert, 2009; Lenz, 2010). Bland et al. (2012) noted that the coping strategies utilized by some students to cope with stress are usually not only ineffective but may increase their level of stress. Consequently, research has shown that when students use ineffective coping strategies to handle their stress, they are at a high risk of not completing their college education (Hystad et al., 2009). Since prior research indicates that culture may influence the context of coping (Utsey et al., 2000), consideration of the African American worldview, may therefore be needed (Jackson \& Sears, 1992). An African perspective focuses on different values held by individuals of African descent, such as group orientation, harmony, interconnectedness, and spirituality (Jackson \& Sears, 1992). Zeidner and Saklofske (1996) explicate that the perceived effectiveness of a preferred coping method must be evaluated considering the cultural group values, norms, and world view. For example, Bacchus (2008) critiques the transactional model of coping, the common conceptualization of coping as emotion-focused and problem-focused by Lazarus and Folkman (1985), may not encompass all of the coping behaviors utilized by Black Americans (Bacchus, 2008).

According to Utsey, Adams, Bolden (2000), Africultural coping is thought to consist of four main components: (1) Cognitive - emotional debriefing - which refers to adaptive reactions by African Americans in the attempt to manage perceived environmental stressors; (2) Collective coping - coping behaviors where group-centered activities are used in the management of stressful situations; (3) Spiritual-centered - involves coping behaviors that corresponds to 
spiritual connectedness; and (4) Ritual-centered coping - coping behaviors that involves the use of rituals as a way to cope with stressful situations . As Greer (2007) explains, the question of whether a coping strategy is functional or dysfunctional may best be comprehended by considering the unique experiences of a cultural group, such as Black Americans. Greer (2007) further asserts that culture-specific coping increases specificity compared to popular measures of coping.

\section{Present Study and Hypotheses}

Multiple researchers (e.g., Banks \& Hughes, 2013; Bramston \& Fogarty, 2000) suggest that individuals with disabilities encounter a wider range of stressors when compared to people without disabilities. Black American students with disabilities at PWI's enter into two belligerent situations - those extra stressors experienced as a result of being a Black American college student in PWI (Greer \& Chwalisz, 2007) and the additional stressors that come from the disability status (Banks \& Hughes, 2013). Previous research reports that individuals with disabilities experience a lack of access to resources (Prince, Patel, Saxena, et al. 2007) and are more prone to experience social disadvantage (Killen, Rutland, \& Yip, 2016). Research also shows that Black Americans students may be less likely to approach the systemic resources (e.g., university counseling centers; Masuda et al., 2009; Reid \& Radhakrishnan, 2003) or authorities (e.g., professors) to address their stress and cope with it, due to their cultural mistrust that Eurocentric, White-centered system and authorities may not be willing or capable of understanding and assisting them with their struggles (Whaley, 2001). Then, Black American students with disabilities would experience not only twice as many stressors but also have limited resources available to use for coping due to a higher level of perceived and real barriers (Blanchett, Mumford, \& Beachum 2005). Thus, this study will examine the stress and coping 
strategies of Black American students with and without disability status. Specifically, I propose the following hypotheses.

\section{Hypothesis 1 (H1)}

Black American students with disability will show higher level of perceived stress than Black American Students without disability.

Underserved populations such as Black Americans may be at an increased risk for perceived stress due to high exposure to unique stressors such as discrimination, isolation, and racism (Arthur, 2007). Black Americans living with disabilities have to deal with a double burden; the stress of being a racial minority and the stress stemming from their disability (HHS, 2011). Research indicates that racial minorities with disabilities encounter several barriers in their attempt to obtain the services they need (Magaña et al. 2012). This leaves Black American students with disabilities especially vulnerable to the impact of perceived stress both due to increase exposure to minority status stress and limited access to resources to deal with the effects of stress. According to a research report by Gorman (1999), students with disabilities feel they have to work harder compared to other students because they have to deal with a double workload; thus their disability and their studies. From the previous studies, it logically follows that, Black American students with disability may experience more stressors as a result of their double minority status, and more stressors experienced in turn, will predispose Black American students with disabilities to perceiving most situations as stressful.

\section{Hypothesis 2 (H2)}

Racial minority status stress and disability-related minority stress would be associated with perceived stress. 
Black Americans report experiencing higher degree of discrimination compared to their European American peers because of their racial minority status (Reid \& Smalls, 2004).

Minority identity characteristic (e.g. disability) could be an important effect modifier in the stress process according to Meyer (2003). General support for the hypothesis comes from studies suggesting that minority identity such as disability leads to additional stressors that make individuals to perceive self as a devalued minority (Esses \& Beaufoy, 1994). I therefore assume Black Americans with disabilities will be more sensitive to report their racial minority status and disability as source of stress. A relationship will therefore exist between racial minority stressors and disability-related stressors; together these characteristics would interact in predicting the overall perceive stress level by influencing thoughts or feelings about how much stress they are challenged with over a given time.

\section{Hypothesis 3 (H3)}

Africultural coping would moderate the relationship between minority stressors and perceived stress for the Black American students. Specifically, spiritual-centered coping and collective coping would serve as a buffer by weakening the relationship between minority status stressors and perceived stress.

Utsey et al. (2007) revealed that collective coping and spiritual-centered coping uniquely predicted the quality of life outcomes for Black Americans well beyond conventional protective factors (e.g., resilience, social connections, confidence). Utsey et al. (2000) in their development of the Africultural Coping Systems Inventory (ACSI) found Spiritual-Centered Coping and Collective Coping to be significantly positively correlated to the problem-focused coping. In terms of emotional reactions and performance levels in a stressful situation, problem-focused coping has been considered to be more effective than emotion-focused (Zeidner, 2010). A 
research investigation by Jarama (1996) showed problem-focused coping (active coping) to be a significant predictor of good mental health for Black Americans with disabilities. Zea et al. (1996) also found active coping (similar to problem-focused coping) and social support satisfaction to significantly predict depression for Black Americans with disabilities. Also, Siegel, et al. (2001) explicates that religious belief may enhance individuals with disabilities ability to cope with stress by encouraging their sense of control. I therefore, hypothesizes spiritual-centered coping and collective coping to moderate the positive relationship hypothesize between minority stress and perceived stress.

\section{Research Question (R 1)}

I also seek to explore the research question: Do Black American students with disabilities differ from Black American students without disabilities in terms of the type of Africultural coping strategies used in handling stress?

\section{Relevance of the Research}

It is beneficial to study the major stressors that contribute to negative outcomes for Black American students with disabilities so that researchers, college professors and policymakers can gain a better understanding of these factors. It is equally important to examine coping strategies that lead to the success of Black American students if we are to increase the numbers of Black American students who successfully pursue and complete postsecondary education at predominantly White college or universities. Drum et al., (2001) assert that disability makes up the largest underserved group in the United States ( 1 in 5 individuals) and intersects with all historically disadvantaged racial groups. For instance, Black American students with disabilities have low retention rates compared to those Black American Students without disabilities (National Center for Special Education Research, 2011). 
According to Lenz (2010), a tremendous effort should be made by college mental health counselors to understand the diverse backgrounds their clients come from and how their backgrounds influence the challenges they face while in college. Although psychotherapy can be very helpful for managing stress, Black Americans have been found not likely to seek services from formal mental health providers (Wang et al., 2005) due to cultural mistrust (Whaley, 2001), and lack of belief in the effectiveness of treatment (Gonzalez et al., 2011). Black American students' as a result tend to rely on other forms of support for coping with stress including friends, family, and church (Whaley, 2001).

Higher educational institutions need to put in extra work to understand and meet the different needs of its diverse student populations (Bruinuiks et al., 2010). With limited research available that considers how Black American students cope with stress by their ability/disability status, this study will add to the body of knowledge. Subsequently, if data from the research reveals a significant difference in the way Black American students with and without disabilities cope with stress, this research may be able to provide information that could assist colleges to develop specialized programs and services to help this subgroup of students cope effectively with stress. Research results could also be used to explore what each group of Black American students wants from interventions targeting stress and which interventions they view as helpful or less helpful. 
Figure 1

The Hypothetical Model for H2

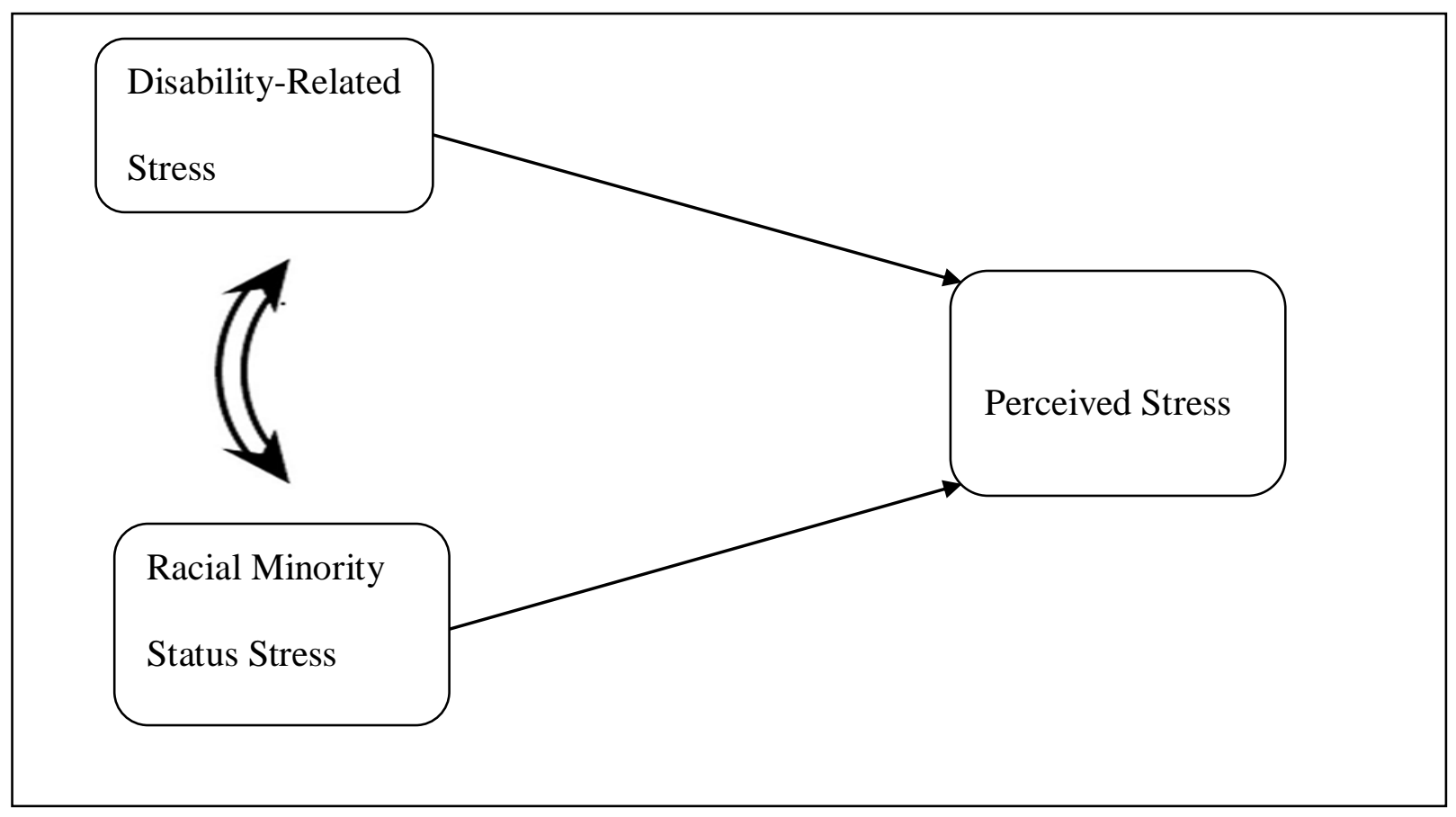


Figure 2

The Hypothetical Model for H3

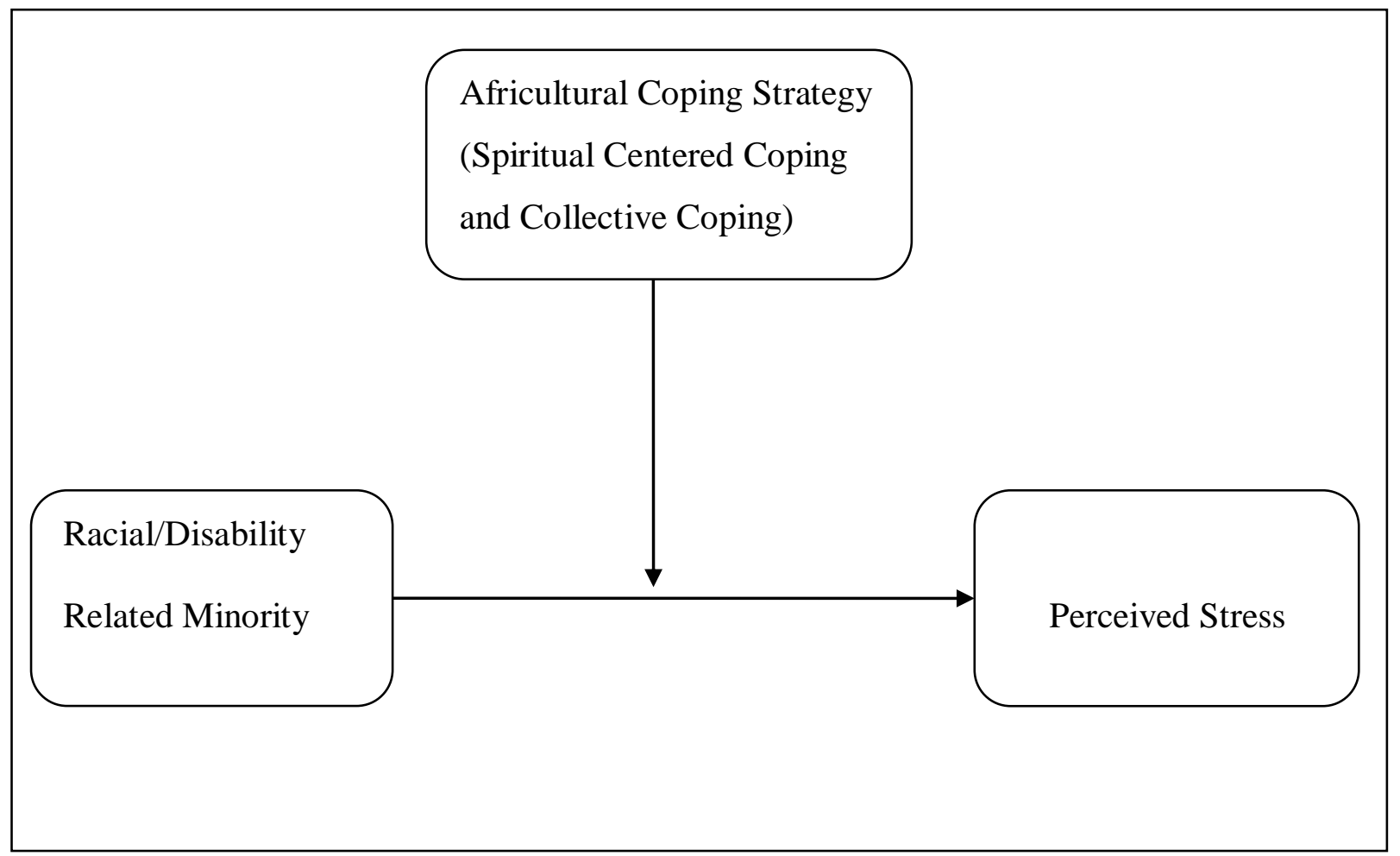




\section{CHAPTER II: REVIEW OF RELATED LITERATURE}

\section{The Concept of Stress}

Stress involves a wide range of processes from perceiving potentially challenging life events (i.e., stressors) to developing stress responses (e.g., bodily arousal; Zajacova et al., 2005). LaMontagne et al. (2010) explained that while there is no universally accepted definition for stress, most theories however propose that stress results from the individual being exposed to stressors in the environment. Lazarus and Cohen (1977) defined stressors as demands made by the internal or external environment that interrupts the balance, hence affecting physical and psychological well-being and requiring steps to restore balance. According to Meyer (2003), conditions and events that cause change and demands that an individual adapts to the new life circumstance or situation are referred to as stressors.

\section{Perception of Stressors}

According to Lazarus' (1990) theory-based stress measurement, the way individuals cope with stress is influenced by how they perceive the stress in their lives. Feldman (2004) explicates that no single level of stress exists that is optimal for everyone. Cunningham (2000) noted that stress is subjective and variations exist for stressors, that is, what may be considered stressful to one person may be perceived as no threat to another individual. Kaufman (2006) also defined stress as an internal state of tension resultant of perceptions. The perceptions an individual has about a major life event, carries more weight on impacting the level of stress they may experience compared to the frequency of the major life event occurrence (Kaufman, 2006). Perceived stress is subjective, and it is as a result of individuals appraising demands of a stressor as likely to exceed their capacity to effectively respond. 
Ross (2010) provides a further explanation that what an individual may consider stressful at a particular point in time may not be perceived as stressful by the same individual at another point in time. Stress may, therefore, be moderated based on factors like a person's level of confidence, personality, coping strategy or availability of social support. Perceiving demands as stressful is, therefore, more salient in starting a stress response than the objective demand which an individual may choose to either evaluate as stressful or not stressful. Cohen et al. (1983) also shared that the challenging experiences in daily life that most people are likely to perceive as tasking and exceeding their coping capacity are referred to as perceived general stress.

\section{Stress Response}

A stress response is the negative physiological and mental health outcome resulting from the prolonged experience of stress (Cohen, Kamarck \& Mermelstein, 1983). Most people recognize stress in the form of acute stress. Acute stress may usually reveal itself through tension, pressure, headaches, and emotional upset. The duration of acute stress is very short therefore it is generally not considered as a health risk looking at its limitation by time. Chronic stress has however been shown to decrease life expectancy (Houtman, Jettingtonhoff, \& Cedillo, 2007). Emotional response to stress may be accompanied by symptoms of constantly feeling overwhelmed, short temper, general unhappiness, and the inability to relax. A constant state of mental stress can lead to serious mental disorders (Mills et al., 2008). Stress can be a physical response to events that happen in a person's life. Research shows stress to be a contributing factor to several physical disorders like migraine headaches, heart disease, high blood pressure, strokes, and gastrointestinal disorders (Krantz \& McCeney, 2002). 


\section{Minority Stress}

Meyer (2003) defines minority stress as the additional stress experienced by individuals from stigmatized social categories because of their minority position. Similarly, Salami and Walker (2010) describe minority stress as an experience that is connected to identifying with a group that has historically been the target of discrimination. According to Phinney and Hass (2003), minority stress is one source of stress that diverse groups of students may encounter as a result of their minority status. Being White in Northern America and Western societies is the racial manifestation that may provoke the least pressure to justify self at high achieving programs, university or work (Köllen, 2014). Ethnic minority students in a PWI may, therefore, be under the stress to prove their qualifications in high achieving class or universities (stereotype threat) due to some preconceived stereotypes about the performance of some ethnic minority groups especially Black Americans (Arbona \& Nora, 2007). Racial/ethnic minorities may also experience prejudice, discrimination, unequal socioeconomic status, and health disparities due to their minority status (Meyer, 2013; Meyer \& Northridge, 2007; Williams and Williams-Morris, 2000).

According to Meyer (2013), several minority stress processes converge with the general stressors common to all people in society thereby compounding the stress faced by minorities. Aranda and Rebello-Gil (2004) further explain that minority stress is usually experienced as a result of the attitudes and treatment by those individuals who see minorities through a stereotypical lens and apply those stereotypes when they have contact with them. Carter (2007) adds that minority stress involves a minority experiencing a hostile cultural environment, especially if they are in a predominantly White institution. 
Applying the social stress theory (Dohrenwend, 1998b), Dohrenwend (2000)

distinguished between distal stress and proximal stress experienced by minorities. Distal stress processes include those stressful situations considered external to the minority individual, such as experiences with rejection, prejudice, and discrimination. Proximal stress processes, on the other hand, are internal, and usually comes about as a result of distal stressors (Dohrenwend, 2000). Example of proximal stress may include the anxiety feelings about prejudice, and negative feelings about one's minority group.

\section{Stress Experienced By Black Americans}

United States citizens who trace their ancestry to Sub-Saharan African origin are considered Black Americans (Salas, Carracedo, Richards, \& Macaulay, 2005). They have been referred to as Colored, Afro-Americans, African Americans as well as Black Americans. In understanding stress among Black Americans, Jackson and Sears (1992) suggested that it is imperative to be knowledgeable about Africentric worldview since cultural values may define a stressful situation, shape cognitive appraisals of stress, and may also guide coping behaviors (Jackson \& Sears, 1992). Among others, Black Americans appear to have a long story of experiencing minority stress in America dating from the years of slavery (Cokley et al., 2013).

Several reasons account for why Black Americans tend to have higher stress levels. A few of the causes could be due to a person of color being visibly a minority (token status) in an environment occupied by non-ethnic minority populations (Cokley et al., 2013), and firsthand experiences of racial microaggressions (Williams \& Jackson, 2005). Fernandez and Roesch (2006) in their research revealed Black Americans reported the highest level of lifetime discrimination compared to other ethnic groups and they appraised racial discrimination as more 
stressful. Most of the incidents of discrimination reported by Black American students according to Swim et al (2003) consist of being ignored, overlooked, followed, or stared at.

Also, Roberts, Gilman, Breslau, Breslau, and Koenen (2011) found Black Americans to have higher incidents of PTSD stemming from discrimination when compared to Caucasians and Asians. Swim et al. (2003) found that, being starred at in social settings was the most common type of racist incident Black Americans in PWIs reported. In addition, Black American students may experience low faculty expectations while studying at PWI's because of the possible stereotype of low intelligence (Ancis, Sedlacek, \& Mohr, 2000). These American students are therefore challenged with an additional stressor of having to disconfirm such negative stereotypes about their group.

According to Wei et al., (2012) stereotype threat is also a type of stressor Black American students experience in PWI's . This includes not wanting to be appraised as "acting too Black" by their White colleagues or professors, in addition to not wanting to be appraised as "acting too White" by other Black Americans in the environment. When Black American students are expected to present themselves in certain ways when observed through stereotypical lenses, this may compound their stress in the academic environment. Considering the numerous negative stereotypes already given to the Black American race (Steele, 2003), stereotype threat may, therefore, be one major stressor for Black American students attending PWIs. For example, Black American students may be under constant stress to prove that they are intelligent as a result of peers' beliefs that their admission was as a result of racial quota or because of the low expectations some faculty may have about their abilities due to the stereotype of low intelligence for Black people (Ancis, Sedlacek, \& Mohr, 2000). 
Wei et al. (2012) explicate that minorities may experience stress by assuming the need to prove themselves to the majority culture they find themselves in. Stress as a result of the perceived insensitivity of peers or faculty and questions of belonging on a college campus not only fuel stereotype threat but can also contribute to Imposter Phenomenon (IP) among Black college students (Cockley et al., 2013). For instance, these minority students in their pursuit to disconfirm stereotype threats about their group may feel like intellectual frauds if they encounter difficulties adjusting to the demanding nature of college life. According to Clance (1985), these students may struggle to internalize their accomplishments and may start to question their intelligence regardless of past scholastic achievements (Clance, 1985). Among Black American students, impostor syndrome has been associated with depressive symptoms (Austin, Clark, Ross, \& Taylor, 2009).

Although not all Black Americans maintain low socioeconomic status, the percentage of Black Americans in poverty is higher than their White counterparts (NCES, 2016), and low socioeconomic status has been shown to compound the stress experienced by Black Americans (NCES, 2016). Among Black Americans in particular, poverty is a significant source of stress (Williams \& Jackson, 2005). Even before most Black American students enter college, they are already exposed to stressors associated with financial difficulty (Greer \& Brown, 2011).

Many Black American students experience additional stress as a result of their race, and this has been linked to negative psychological outcomes such as general psychological distress, low self-esteem, and low levels of life satisfaction (Kwate et al., 2003). Laurence, Williams, and Eiland (2009) identified a higher level of stress was identified for the Black American graduate students compared to other groups of graduate students. Smedley, Myers, \& Harrell (1993) explain that Black Americans students' ability to adapt to the PWI's they select is impacted by 
the higher stress they face. According to Clark, Anderson, Clark, and Williams (1999), racism magnifies psychological responses to psychosocial difficulties and exacerbate levels of stress. Several research findings indicate that Black Americans who are continuously exposed to racial discrimination are more likely to evaluate stressful situations as threats rather than challenges and to engage in dysfunctional coping behaviors which in turn increase the likelihood of negative affective responses (Pieterse \& Carter, 2007; Sanders-Thompson, 2006).

\section{Stress Experienced by Individuals with Disability}

College students with disabilities may be highly at risk in terms of stress, given that these students are challenged with the same stressors as the general college student population plus having to deal with additional impairment in some other areas of their lives. Despite the several successes of numerous disability support programs, the unique needs of some students with disabilities remain unmet. For example, the U.S. Department of Education, National Center for Education Statistics (2003b) research revealed that $22 \%$ of college students with disabilities reported not receiving the services they needed. Also, a research report by Sharpe et al. (2005) showed that although $69 \%$ of students with disabilities were satisfied with the services they received, $35 \%$, however, reported the denial of services believed to be necessary.

The World Health Organization (WHO) estimates that approximately one billion people or between 10 to 15 percent of the world's population live with disabilities. This makes people living with disabilities the world's largest minority (WHO, 2011; UN, 2012). The WHO also explains that the term disability comprises several components like impairments, activity limitation and participation restrictions. Disability according to WHO (2001) may, therefore, be defined as a problem in body function or structure, a difficulty encountered by a person in executing a task, or a problem experienced by a person in the involvement in a general life 
situation. Some individuals may be born with disabilities, while others may develop their disabilities later in life. The Global Burden of Diseases (GBD) describes disability as loss of health, where the term health defines the ability to function in health domains such as cognition, mobility, hearing and vision (Murray, Lopez, \& World Health Organization, 1996). According to Crisp (2002), disability poses limitations that interfere with an individual's ability, for example, to see, hear, walk or learn. A disability could either be visible or invisible and there are also variations with regards to the causes and severity of the various disabilities.

There are several kinds of disability (International Classification of Functioning, Disability, and Health [ICF], 2001). The different categories of disabilities include physical disabilities, psychological disabilities, intellectual disabilities, sensory disabilities, medical or health disabilities (ICF, 2001). Sensory disability involves the disability of one or more senses (e.g. sight, hearing, smell, touch, taste). Examples of sensory disabilities include but not limited to anosmia, somatosensory loss, blindness, vision loss, deafness. Intellectual disabilities may involve sub-average or significant limitations in the skills needed to live and work in the community, including self-care, social skills, safety, and self-direction. Psychological or psychiatric disability, on the other hand, refers to a wide range of either psychological or behavioral problems which may include mood swings, depression, compromised assessment of reality, anxiety and many more. Physical or mobility disability may involve impairment of some aspect of an individual's physical functioning. In most cases, their mobility, dexterity or stamina is affected by this disability. Individuals with physical or mobility disabilities may find it stressful to participate when they encounter physical barriers. Medical or health-related disabilities involve conditions compromising one or more of the body's systems. Body systems that could be affected include immunological, neurological, respiratory system and circulatory 
systems. Examples of health disabilities include but not limited to cancer, diabetes, hypertension, leukemia, respiratory disorders, and seizure disorders.

Prince, Patel, Saxena, et al. (2007) explained that living with chronic disease, injury or long-term disability can mean several additional burdens, including the threat of declining health, lifestyle changes, stigma, reduced social support and participation, breakdown of relationships, and isolation. People with disabilities experience discrimination in critical areas like employment, housing, and transportation. Data released in 2016 from the American Psychological Association (APA) Stress in America show that adults with disabilities reported an average stress level of 5.5 on a 10-point scale, while an average stress level of 4.8 on a 10-point scale was reported by adults without disabilities (APA, 2015). Also, individuals with disabilities are more vulnerable to be abused or exploited as a result of limitations to either their physical, sensory or mental function (Fuller-Thomson \& Brennenstuhl, 2012).

\section{Stress Experienced By Racial Minorities with Disabilities}

Life for members of racial minority individuals living with a disability has been described by the US Department of Health and Human Services (HHS) advisory committee for minority health as a "double burden" as a result of the additional challenges this subpopulation encounters (HHS, 2011). Disability rates have been found to increase steadily among the ethnic minority population. Research reveals Black Americans and American Indians have the highest rate of experiencing disability in the United States and this pattern is believed to be as a result of economic disparities and racial discrimination (Anderson, 2013). According to Asbury and colleagues (1992), inaccessible health care system, greater risk of physical injury in terms of living conditions, poor nutrition and types of employment situation may all be contributing factors for increase disability rates among the ethnic minorities. 
Research indicates that racial minorities with disabilities encounter several barriers in their attempt to obtain health care services (Magaña et al. 2012) as well as quality rehabilitative and specialty services (Balcazar et al. 2012; Magaña et al. 2012). Individuals with dual-minority status are vulnerable to stress in two folds; thus having to contend with the stressors associated with racial minority status as well as the unique stressors they experience as individuals living with a disability (Blanchett, Mumford, \& Beachum, 2005). For instance, a racial minority with a disability will have to deal with the stress as a result of their race (discrimination, stereotype threat) as well as handle the stress stemming from their disability (being labeled weak or incompetent, harassment). This lends support to what the HHS advisory committee on minority health refers to as the double burden faced by people of color with disabilities (HHS, 2011).

Several research data already indicate that racial minorities with disabilities usually come from a household with very low socioeconomic income status compared to racial majorities with no disabilities (NDI, 2017). This hinders their ability to get the needed assistance on their disability like diabetic test strips, medical check-ups and adaptive equipment like hearing aids, and prosthetic limbs for their day to day living. Minorities with disabilities, especially Black Americans with disabilities have been found to rely on public transport more often than other racial groups (Graham, Keys and McMahon, 2014). Inadequate transportation is a major obstacle to engage in community life, follow up with medical appointments and participate in other healthy lifestyle activities (e.g., physical fitness activities). For instance, Belgrave (1998) explains that most Black Americans resides in the inner cities where access to public transportation is often limited. Thus, rather than to struggle with the barrier in getting accessible transportation, it is usually much easier for these individuals not to go to medical and rehabilitation appointments (Belgrave, 1998). These external circumstances place racial 
minorities with disabilities at a disadvantage causing them to be handicap by their disability. It is helpful to acknowledge that when disability handicaps people, it may prevent them from carrying out activities which could lead to frustration in some cases and ultimately stress (Crisp, 2002).

\section{Coping Strategies}

Looking at the detrimental effects of stress on the general well-being of individuals, it is therefore important to handle stress occurrence effectively. According to Greer and Chwalisz (2007), coping is the cognitive and behavioral attempts used by individuals to manage, reduce, or endure the internal and external demands of stressful situations. According to the transactional model of stress and coping (Lazarus \& Folkman, 1984), coping consists of two major functions: the handling of the stressor that is causing the distress (i.e. problem-focused coping) and the regulation of emotions caused by the stressor (i.e. emotion-focused coping). When a person is faced with a stressful situation, several different coping strategies may be used. These strategies may include the use of instrumental social support, planning, religious coping, humor, substance use, denial, use of emotional social support, positive reinterpretation and growth (Carver et al, 1989).

In problem-focused coping (i.e., active coping), the individual seeks to find the source of stress, generate alternatives to the stressor and finally proceed with actions needed to minimize the stressful situation. This coping is used much often when an individual believes they can do something about the stressor (Carver et al., 1989). Struthers, Perry, and Menec (2000) noted that when students handle their academic stress using problem-focused coping, they are more motivated and eventually, their academic performance is much higher compared to students who utilize emotion-focused coping strategy. Lenz (2010) also found that college students perceived 
problem-focused coping as being the most effective, functional, and frequently used coping strategy (Lenz, 2010).

Emotion-focused coping strategies entail efforts an individual use to alleviate the emotional distress or regulate the emotional consequences of a stressful or potentially stressful event (Lenz, 2010). An individual may, therefore, focus on handling the emotional aspect of the stress instead of targeting the source stressor (Folkman \& Lazarus, 1984). Carver et al. (1989) explain that emotion-focused coping may involve seeking social support from family or friends, sharing one's feelings, resorting to religion, accepting the situation, denying the situation, or positive reinterpretation of the situation. People are inclined to select emotion-focused coping strategies when the situation seems uncontrollable when appraised (Lenz, 2010).

Avoidance coping (disengagement) comes about if an individual fail to handle either the stressor or the emotional impact of the stressor directly. Carver et al. (1989) explicate that avoidant coping may involve an individual surrendering any effort to change or handle the stressor. An individual may focus on another task to avoid the emotional impact of the source of stress or will avoid stress rather than handle it (Heiman, 2004). Avoidance coping could also involve the use of humor, drinking alcohol or taking drugs, and venting of emotions (Carver et al., 1989). Lenz (2010) also noted that students rated avoidance coping ineffective and use it less frequently compared to problem-focused coping (active coping) and emotional-focused coping. Avoidant coping may only be helpful in situations where an individual has no control over the stressor and disengagement from the stressor is needed to buffer the stressor. Carver et al. (1989) explain that avoidance coping may not be initially maladaptive but may become so if an individual uses it as a long-term coping strategy. 


\section{Africultural Coping Strategies}

There is an increasing number of researches on how Black Americans cope with societal stressors and environmental stressors (Greer, Ricks, \& Baylor, 2015; Oliver, Datta, \& Baldwin, 2017). According to Utsey et al. (2000), culture plays a role in stress and coping responses. Utsey et al. (2000) define Africultural coping as coping behaviors that reflect the worldviews of Africans which is often utilized by Black Americans. According to Utsey, Adams, Bolden (2000), Africultural coping is made up of four main components: (1) Cognitive - emotional debriefing - which refers to adaptive reactions by African Americans in the attempt to manage perceived environmental stressors; (2) Collective coping - coping behaviors where groupcentered activities are used in the management of stressful situations; (3) Spiritual-centered involves coping behaviors that corresponds to spiritual connectedness; and (4) ritual-centered coping - coping behaviors that involves the use of rituals as a way to cope with stressful situations .

Existing research that utilized the Africultural Coping System Inventory (ACSI) revealed that some types of culture-specific coping may be associated with positive outcomes for Black Americans. For instance, research conducted by Utsey et al. (2007) revealed that collective coping and spiritual-centered coping uniquely predicted the quality of life outcomes well beyond conventional protective factors. Cognitive-emotional coping was found by Thomas et al. (2008) to partially mediate the relationship between gendered racism and psychological distress for Black American women. These findings highlight the importance of Africultural coping in explaining stress outcomes for Black American students.

Primarily, Black Americans have been documented to use spirituality and other forms of social support to cope much often (Spencer, Fegley, \& Harpalani, 2003). Young, Griffith, \& 
Williams (2003) found that Black Americans tended to seek help from church and clergy as a way to manage their mental health issues. To find the protective factors in buffering stress amongst low-income Black American youth, Grant et al. (2000) surveyed 224 Black American adolescents from sixth to eighth grade. The researchers found religious involvement to be a protective factor for Black American girls but not for the boys. Pollock, Kazman, and Deuster (2015) researched the relationship between family function and stress for a sample size of 255 Black Americans. The researchers identified a familial relationship to be a key component of social support for Black Americans. Reynolds et al. (2010) in their research also showed that the involvement of Black American students in race-based student organizations like the Black Student Union which honors their cultural identity helps them to handle the stress associated with being a minority college student much better.

\section{Coping Strategies Used by Individuals Challenged with Disability}

Linveh and Wilson (2003) explain that coping with a disability is an individualized process. Two people with the same disabilities could use different coping strategies and experience different outcomes. In recent years, there have been a growing number of interests in the process by which individuals living with various forms of disability cope with them (e.g., Andersson and Hägnebo, 2003; Firth \& Frydenberg, 2008). For example, Greaves (1998) found that students with learning disabilities showed higher than average use of emotional-focused coping strategies and lower use of problem-focused coping strategies.

Siegel, Anderman, and Schrimshaw (2001) found, on the other hand, that religion as a frequent way of coping for individuals with a disability. Religious belief was noted to increase an individual's coping resources for handling their disability-related stress through the enhancement of self-worth and sense of control (Siegel, Anderman, \& Schrimshaw, 2001). In general, among 
individuals living with disabling conditions, evidence from research report shows avoidant coping strategies and emotional focused coping strategies such as wishful thinking are associated with poorer outcomes, whereas problem-focused coping strategies have revealed a more positive outcome (Jarama, 1996; Zautra and Manne, 1992). Jarama (1996) researched the role of problem-focused coping (active coping) play on mental health and vocational outcomes among Black Americans and Latinos with diverse disabling conditions. The result revealed problemfocused coping to be a significant predictor of good mental health.

Belgrave and colleagues (1994) in their research found that Black Americans with disabilities were more satisfied with material and cognitive forms of support compared to White Americans with disabilities. The researchers also noted that Black Americans with disabilities were more likely to report family and relatives as members of their social network than White Americans (Belgrave et al., 1994). 


\section{CHAPTER III: METHOD}

\section{Population and Sample Procedure}

The target population for the study was Black/African American college age students with different ability status. Students who identified themselves as Black/African Americans were recruited from two large universities in the Midwestern region of the United States. Black immigrants from African or Caribbean countries were not included in the sample. An e-mail with brief information concerning the purpose of the study was sent out to students who self-identified as African American. A link to the informed consent and survey instruments was contained in the recruitment e-mail. A follow-up e-mail was sent few weeks later to the e-mail pool. Prior to completing the survey materials, participants were requested to read and click "agree" to consent their participation in the research. Participants only gained access to the remainder of the online Qualtric survey after they checked the "yes" box noting their consent to participate in the study. As an incentive, research participants who completed the study have the chance to win $5 \$ 20$ or $10 \$ 10$ cash prices upon agreement to participate in the prize drawing.

\section{Data Screening}

Using SPSS Version 24 to identify out of range values, amounts and patterns of missing data, a data screening was conducted by examining all variables' descriptive statistics following Tabachnick and Fidell (2007) recommendation. Two hundred and eight participants consented to the study. Thirty-two participants (15\%) were removed from the final data set because their eligibility to participate in the study could not be verified due to not identifying as Black/African American or missing information on their racial group. Forty-one participants (20\%) were removed because they did not complete all the required measures. Four participants $(<1 \%)$ were removed during data screening as a result of out of range values. This resulted in a final sample 
of 123 participants. When examining a moderation model using a multiple linear regression equation, a power analysis using G Power software determined at least 29 respondents with disability were needed to detect a medium sized effect $(0.30)$ at an $80 \%$ power level. A total of thirty- nine $(31.7 \%)$ participants met the WHODAS criteria for moderate to severe disability. Out of the thirty-nine Black American students with disability, twenty-three self identified as having disability and met the average domain scores of moderate (2) to severe (3) disability on the WHODAS 2.0 36- item self-administered version. The remaining sixteen participants, although they did not self-identify as someone with disability, were screened by the WHODAS 2.0 to show severe disability (4) on the average domain score. Forty-six (37\%) participants were from institution "A" and seventy-seven (63\%) of participants were from institution "B". Twenty-nine (24\%) participants identified as males and ninety-four (76\%) participants identified as females. Six (4.9\%) participant identified as married; Seventy-two (58.5\%) identified as single and not dating; Two (1.6\%) participants indentified as divorced; and forty-three (35\%) participant identified as not married but dating.

\section{Instrumentation}

\section{Perceived Stress Scale (PSS)}

The perceived stress levels of Black American students with disabilities and those without disabilities were measured using the Perceived Stress Scale (PSS). The PSS is a 10-item instrument developed by Cohen, Klamarck, and Memmelstein (1983) to assess the degree to which individuals perceive life-events as stressful and is based on Lazarus' transactional stress model. The Perceived Stress Scale measures the perception students have of their overall level of stress in their lives over the past month. The PSS does not measure specific types of stress an individual's experience; rather it is a global measure of felt stress. Items on the Perceived Stress 
Scale are rated via a 5-point Likert - type scale ranging from 0 (never) to 4 (very often). A higher score suggests a higher level of perceived stress. A sample item is "In the last month, how often have you found that you could not cope with all the things that you had to do?" Cohen et al., (1983) showed the internal consistency coefficient was .91 in a sample of college students. Pieterse and Carter (2007) reported coefficient alpha to be .76 for Black Americans. A positive association with psychological distress among Black Americans in the research conducted by Pieterse and Carter (2007) supports the construct validity. The internal consistency coefficient in this study was .86 .

\section{Minority Student Stress Scale (MSSS)}

Minority status stressors were measured using the Minority Student Stress Scale (MSSS). The MSSS is a 33- item scale normed on ethnic minority students that measures their minorityspecific stressors rated on a 6-point Likert-type scale ranging from $0=$ does not apply to 5=extremely stressful (Smedley et al., 1993). Score range from a total of 0 to 165 and high scores indicate higher levels of stressors experienced due to racial/ethnic minority student status. Subscales include social climate stressors (e.g., "few students of my race are in my class"), achievement stress subscale (e.g., "feeling less intelligent or less capable than others"), racism and discrimination stress subscale (e.g., "Being treated rudely or unfairly because of my race"), interracial stress subscale (e.g., "White people expecting me to be a certain way because of my race") and intragroup or within-group stress subscale (e.g., "Pressures to show loyalty to my race"). In scoring the MSSS, both subscale scores and/or total scores can be used for analysis. Each subscale is scored to show high stress among the various subscales. The subscales are averaged together to get the total minority student status stress score. Internal consistency has been reported. Coefficient alphas for Black Americans ranged from .76 to .93 (Smedley et al., 
1993). In other studies, an estimated range of .63 to .92 has been reported as the internal consistency reliability for the MSSS subscale (Cokley et al., 2013; Myers, Morris, \& Cardoza, 2003) and an estimate ranging from .92 to .97 was reported for the total score (Cokley et al., 2013; Greer \& Brown, 2011; Greer \& Chwalisz, 2007). The internal consistency in the current study sample was 96 .

\section{Africultural Coping System Inventory (ACSI)}

Utsey, Adams, and Bolden (2000) developed the Africultural Coping System Inventory (ACSI) to measure Black American's use of culture-specific coping styles. The ACSI is a 30item instrument that is grounded in an Africentric worldview and reflects the values and perspectives of people of African descent. The measure has four subscales unique to the coping of African Americans. The first subscale, Cognitive-Emotional Debriefing includes attempts to manage stressors, such as cognitive efforts to shift thoughts to other things and behavioral attempts to get involved in other activities. For instance, "I sought out people I thought would make me laugh" (Utsey, Adams, \& Bolden, 2000). Cognitive-emotional debriefing is considered an avoidant way of coping since it is related to detachment or denial of issues (Utsey, Adams, \& Bolden, 2000). This study had an internal consistency of .84 for this subscale. The second subscale, Spiritual-Centered Coping, refers to relying upon a connection to spirituality and a relationship with the Creator to cope with stressors. Emphasis is placed on the universal sense of spirituality or deity (e.g., "asked for blessings from a spiritual or religious person"). The internal consistency for spiritual-centered coping for this study was .87. The third subscale, Collective Coping refers to how a person may rely upon others to cope with stress. Items of this subscale reflect the Africultural value of the importance of the group and family (e.g. "remembered what a parent or other relative once said about dealing with these kinds of situations"). Collective 
coping showed an internal consistency of .77 in this research. Lastly, Ritual-Centered coping, which is the fourth subscale, refers to cultural rituals African Americans engage in as a means of coping with stress (e.g., "burned incense for strength and guidance in dealing with the problem"). An internal consistency of .79 was shown for Ritual-Centered coping in this study sample. Respondents are directed to think of a recent stressful situation and to respond to the items using a 4-point Likert-type scale ranging from $0=$ does not apply/did not use to $3=$ used a great deal. Subscale scores are utilized by adding participants' responses to each item on the corresponding subscales. Through exploratory factor analysis and confirmatory factor analysis, the four-factor structure of the ACSI has been supported (Utsey et al., 2000). Cronbach's alpha coefficients ranged from .71 to .80 for the subscales (Utsey et al.,2000). Utsey et al. (2000) established concurrent validity as well through correlations between the ACSI and the Ways of Coping Questionnaire developed (Folkman \& Lazarus, 1985)

\section{World Health Organization Disability Assessment Schedule 2.0 (WHODAS 2)}

WHODAS 2.0 was developed in 1998 by the World Health Organization to assess disability based on the International Classification of Functioning, Disability, and Health (WHODAS II, 2001). It is grounded in the conceptual framework of the ICF and an individual's level of functioning is assessed in six major life domains: mobility, self-care, cognition, getting along, life activities, and participation in society. The 36 item WHODAS 2.0 has been reported to have an internal consistency of .96 (Üstün et al., 2010). The current study sample reported an internal consistency of .96. WHODAS 2.0 comprises of 36 items: 6 items in the "cognition domain" (e.g., difficulty in generally understanding what people say), 5 items in "mobility domain" (e.g., difficulty in getting out from the home), 4 items in "self-care domain" (e.g., difficulty in getting dressed), 5 items assess "getting along and the interaction with the others" 
(e.g., difficulty in maintaining a friendship), 8 items inquire "life activities," (e.g., difficulty in taking care of household responsibilities) and last domain has 8 questions that inquire about "joining in community activities" (e.g., how much of a problem did your family have because of your health problems?) (WHODAS II, 2001). For every item, respondents are asked to answer the level of difficulty they have had in the last 30 days to do something. Items are rated via a 5point Likert - type scale ranging from 1 (none difficulty) to 5 (extremely difficult/cannot). Respondents are required by the WHODAS 2.0 to make attributions about the source of their disability. When completing this scale, people who are neither working nor in school are instructed to skip these items.

\section{Disability-Related Stress Scale (DRSS)}

The DRSS was created by Rhode, Froehlich-Grobe, Hockemeyer, Carlson, and Lee (2012) to sufficiently assess the stress individuals with disabilities experience by capturing the unique stressors the group commonly encounters. Thus, the instrument was developed for a broader group of people living with disabilities to assess both exposure to and the intensity of disability-specific stressors. Although the initial population surveyed to develop the DRSS were individuals with physical limitations as a result of the impaired movement of the upper and lower extremities, Rhode et al. (2012) suggests that other potential applications of the DRSS include examining exposure to and level of stress appraisal by specific groups of individuals with disabilities. In addition, the DRSS could be used to examine whether exposure to disabilityspecific stressors and the impact of stress is related to chronic conditions (i.e., diabetes, cardiovascular disease; Rhode et al., 2012). One-third of the population $(n=40)$ in the pilot study used to develop the DRSS were Black Americans (34.2\%). The instrument comprises of 52 DRSS items and each of the DRSS items contains two questions: "Did this happen?" (yes/no) 
and "How stressful was the event?" which was rated on a 7-point Likert scale ranging from 1 (Not at all stressful) to 7 (Extremely stressful). Respondents are therefore required to indicate whether they have experienced the stressors and if so, they are to rate the intensity of the stress. The DRSS, therefore, produces an "Event score" (total number of events endorsed) and an "Impact score" (sum of subjective ratings of endorsed items) for both parts. The DRSS consists of two parts named based on dimensions of the ICF (Rhode et al., 2012). Part 1 has four subscales identified as Disability Impact (e.g., had to rely on others for financial assistance), Societal Barriers (e.g., was treated differently because of my disability), Participation Limitations (e.g., had difficulty getting into public buildings) and Medical Care Transportation Barriers (e.g., could not afford medical supplies). For Part 2, the two subscales identified are Accommodation barriers and Interpersonal impact (e.g., did not have enough money for home adaptations) and lastly, Employment and Social Service Barriers (e.g., had problems getting needed education or training). 


\section{CHAPTER IV: RESULTS}

\section{Data Analysis}

I inspected the study variables to ensure that several assumptions were met before conducting the study analysis. I assumed a normal distribution for each of the study variables (Osborne \& Waters, 2002). A Shapiro - Wilk's test ( $p>0.05)($ Razali \& Wah, 2011) and a visual inspection of their histogram, normal Q - Q plots and box plots found that the scores of PSS, MSSS, and all of the ACSI subscale scores adhered to a normal curve. DRSS did not show a normal distribution curve. A square root transformation was therefore conducted for DRSS. Following multiple transformations of the DRSS with no improvement to skewness and kurtosis, the original untransformed variable was retained. The use of parametric test was justified since majority of the study variables showed a normal distribution curve with the exception of DRSS.

Multicollinearity was also examined in order to determine if the variables do not have a linear relationship with each other because this may increase the risk for error in the regression equation. I found multicollinearity to not be an issue of concern after completing tests to see if the data met the assumption of collinearity (Minority Student Stress Score, Tolerance =. 54, VIF $=1.85$; Disability Relates Stress Score, Tolerance $=.56, V I F=1.80 ;$ Cognitive-Emotional Debriefing Subscale Score, Tolerance = .57, VIF = 1.75; Spiritual Centered Subscale Score, Tolerance $=.42, V I F=2.38 ;$ Collective Coping Subscale Score, Tolerance $=.33, V I F=3.04$; Ritual Centered Subscale Score, Tolerance $=.30, V I F=3.31)$.

Table 1 illustrates mean, standard deviations, and $\mathrm{N}$ for each of the study variables in the entire sample, those with disabilities, and those without disabilities. Table 2 illustrates perceived stress level difference between the Black American students with and without disabilities. Table 
3, 4 and 5 also shows correlation coefficients between study variables. Table 6 and Table 7

illustrate results for moderation. Table 8 illustrates difference in coping strategies utilized.

Table 1

Descriptive Statistics of Study Variables among Black Americans with and without Disabilities

\begin{tabular}{|c|c|c|c|c|c|c|}
\hline \multirow[b]{2}{*}{ Variable } & \multicolumn{3}{|c|}{$\begin{array}{c}\text { Black American Students } \\
\text { With Disabilities }\end{array}$} & \multicolumn{3}{|c|}{$\begin{array}{c}\text { Black American Students } \\
\text { Without Disabilities }\end{array}$} \\
\hline & $\mathrm{n}$ & $\mathrm{M}$ & $\mathrm{SD}$ & $\mathrm{n}$ & $\mathrm{M}$ & SD \\
\hline Perceived Stress & 39 & 21.85 & 5.55 & 84 & 19.13 & 6.72 \\
\hline $\begin{array}{l}\text { Racial Minority } \\
\text { Student Stress }\end{array}$ & 37 & 98.84 & 36.75 & 81 & 83.02 & 32.62 \\
\hline $\begin{array}{l}\text { Cognitive-Emotional } \\
\text { Debriefing }\end{array}$ & 37 & 17.70 & 7.07 & 82 & 15.90 & 7.05 \\
\hline $\begin{array}{l}\text { Spiritual-Centered } \\
\text { Coping }\end{array}$ & 37 & 9.40 & 7.34 & 82 & 7.60 & 5.62 \\
\hline $\begin{array}{l}\text { Collective- Centered } \\
\text { Coping }\end{array}$ & 37 & 12.49 & 5.66 & 82 & 10.98 & 4.56 \\
\hline $\begin{array}{l}\text { Ritual-Centered } \\
\text { Coping }\end{array}$ & 37 & 1.97 & 2.93 & 82 & .55 & 1.13 \\
\hline
\end{tabular}

Note: $\mathrm{n}=$ Sample Size, $\mathrm{SD}=$ Stand Deviation, $\mathrm{M}=$ Mean

Table 2

T-test Results for Equality of Means Comparing Black Americans with and without Disabilities on Level of Perceived Stress Scores

\begin{tabular}{|c|c|c|c|c|c|c|c|c|}
\hline \multirow[b]{2}{*}{ Variable } & \multicolumn{3}{|c|}{$\begin{array}{c}\text { Black American Students } \\
\text { With Disabilities }\end{array}$} & \multicolumn{3}{|c|}{$\begin{array}{c}\text { Black American Student } \\
\text { Without Disabilities }\end{array}$} & \multirow[b]{2}{*}{$t(121)$} & \multirow[b]{2}{*}{$p$} \\
\hline & $\mathrm{n}$ & $\mathrm{M}$ & SD & $\mathrm{n}$ & $\mathrm{M}$ & $\mathrm{SD}$ & & \\
\hline Perceived Stress & 39 & 21.85 & 5.55 & 84 & 19.13 & 6.72 & $2.20 *$ & .030 \\
\hline
\end{tabular}


Table 3

Descriptive Statistics and Correlations Between Perceived Stress and Racial Minority Student

Stress

\begin{tabular}{llllllllll}
\hline Variable & $\mathrm{n}$ & $\mathrm{M}$ & $\mathrm{SD}$ & 2 & 3 & 4 & 5 & 6 & 7 \\
\hline 1.Perceived & 123 & 19.99 & 6.48 & $.39^{* *}$ & $.29^{* *}$ & $.28^{* *}$ & $.30^{* *}$ & $.32^{* *}$ & $.48^{* *}$
\end{tabular}

Stress

2.MSS:

$118 \quad 87.98 \quad 34.60 \quad-$

(Total)

3.MSS:

$122 \quad 28.69 \quad 13.02$

(Social Climate)

4. MSS:

$122 \quad 16.30 \quad 7.21$

(Discrimination)

$\begin{array}{llll}\text { 5.MSS: } & 121 & 18.04 & 8.53\end{array}$

(Interracial)

$\begin{array}{llll}\text { 6.MSS: } & 123 & 10.85 & 4.76\end{array}$

(Within-Group)

$\begin{array}{llll}\text { 7.MSS: } & 121 & 14.26 & 7.71\end{array}$

(Achievement)

Note: $\mathrm{n}=$ Sample Size, $\mathrm{SD}=$ Stand Deviation, $\mathrm{M}=$ Mean

**. Correlation is significant at 0.01 level (2- tailed).

Note: $\mathrm{n}=$ Sample Size, $\mathrm{SD}=$ Stand Deviation, $\mathrm{M}=$ Mean, MSS = Racial Minority Student -

Stress. 
Table 4

Descriptive Statistics and Correlations Between Perceived Stress and Disability Related Stress Scale

Scores

\begin{tabular}{llllccccccc}
\hline Variable & $\mathrm{n}$ & $\mathrm{M}$ & $\mathrm{SD}$ & 2 & 3 & 4 & 5 & 6 & 7 & 8 \\
\hline 1.Perceived & 39 & 21.85 & 5.55 & .28 & .33 & $.52 *$ & .14 & .15 & .14 & .24
\end{tabular}

Stress

2.DRSS:

$17 \quad 129.65 \quad 86.33 \quad-$

(Total)

3.DRSS:

$24 \quad 33.08 \quad 15.95$

(Disability-Impact)

4. DRSS:

$19 \quad 23.11 \quad 14.44$

(Societal Barriers)

5.DRSS:

$21 \quad 24.48 \quad 19.82$

(Participate Limit)

6.DRSS:

$19 \quad 23.32 \quad 18.73$

(Medical/Transport)

7.DRSS:

$18 \quad 19.11 \quad 16.00$

(Accommodation)

8.DRSS:

$19 \quad 16.79 \quad 13.46$

(Employment)

*. Correlation is significant at 0.05 level (2- tailed).

Note: $\mathrm{n}=$ Sample Size, $\mathrm{SD}=$ Stand Deviation, $\mathrm{M}=$ Mean, DRSS = Disability Related Stress Scale 
Table 5

Means, Standard Deviations and Correlation between MSSS and DRSS

\begin{tabular}{lccccc}
\hline Measure & $\mathrm{n}$ & $\mathrm{M}$ & $\mathrm{SD}$ & 1 & 2 \\
\hline 1. MSS & 37 & 98.84 & 36.75 & - & $.51^{*}$ \\
$2 . \mathrm{DRSS}$ & 17 & 129.65 & 86.33 & $.51^{*}$ & - \\
\hline
\end{tabular}

*. Correlation is significant at 0.05 level (2- tailed).

Note: $\mathrm{n}=$ Sample Size, $\mathrm{SD}=$ Stand Deviation, $\mathrm{M}=$ Mean, DRSS = Disability Related Stress

Scale $($ Total), MSS = racial Minority Student Stress Scale (Total)

\section{Hypotheses Testing}

\section{Hypothesis 1 (H1)}

H1 was that Black American students with disability would show higher level of perceived stress than Black American Students without disability. An independent sample $t$-test between disability $(n=39,23$ self-identified and 16 not self-identified scoring severe on WHODAS 2.0) and non-disability group on the mean levels of perceived stress scores revealed that Black American students with disability scored significantly higher on perceived stress than those with no disability, $\mathrm{t}(121)=2.20, p=.03$. Thus, $\mathrm{H} 1$ was supported.

\section{Hypothesis 2 (H2)}

$\mathrm{H} 2$ stated that racial minority status stress and disability-related stress would be associated with perceived stress. A correlational analysis showed that racial minority stress was associated significantly with perceived stress in the entire sample, $r(116)=.39, p<.001$. Except for the societal barrier subscale of the DRSS which showed a moderate correlation with perceived stress, $\mathrm{r}(15)=.52, \mathrm{p}=.022$, the remaining subscales together with the total impact 
showed no meaningful association (Table 4). Results also showed significant positive association between racial minority student stress and disability related stress, $\mathrm{r}(14)=.51, \mathrm{p}=.05$.

\section{Hypothesis 3 (H3)}

H3 was that Africultural coping would moderate the relationship between minority stressors and perceived stress for the Black American students with disability. Specifically, spiritual-centered coping and collective coping would serve as a buffer by weakening the relationship between minority status stressors (racial minority stress, disability related stress) and perceived stress.

First, a moderated regression analysis using SPSS PROCESS macro was conducted with racial minority stressors as the independent variable, perceived stress as the dependent variable, and spiritual centered and collective coping strategies as the moderators among the entire sample. For spiritual-centered coping strategy as a moderator, the overall moderation model explained a significant amount of variance in perceived stress scores, $R^{2}=.389, F(3,113)=$ $6.71, p<.001$. The main effect of racial minority student stressors on perceive stress was positive and significant, $\beta=.073$, s.e. $=.017, p<.001$; however, the main effect of spiritual centered coping on perceive stress was not significant, $\beta=.012$, s.e. $=.094, p=.897$. The overall interaction effect between racial minority student stressors and spiritual-centered coping fell short of statistical significance, $\Delta R^{2}=.002, F(1,113)=.29, p=.592$. For collective coping strategy as a moderator of the relationship between racial minority stressors and perceive stress score, the overall moderation model had significant effect of variance in perceived stress score, $R^{2}=.165, F(3,112)=7.39, p<.001$. While racial minority student stressors had a positive and significant main effect on perceive stress scores, $\beta=.070$, s.e. $=.017, p<.001$, the main effect of collective coping on perceive stress was not significant, $\beta=.116$, s.e. $=.120, p=.337$. The 
overall interaction effect between racial minority student stressors and spiritual-centered coping also fell short of statistical significance, $\Delta R^{2}=.008, F(1,112)=1.02, p=.314$.

Second, another moderated regression analysis using SPSS PROCESS macro was conducted with disability-related stressors as the independent variable, perceived stress as the dependent variable, and spiritual centered and collective coping strategies as the moderators among the subsample of Black students with disability. Examining spiritual-centered coping strategy as a moderator of the relationship between disability related stressors and perceive stress score, the overall moderation model fell short of statistical significance, $R^{2}=.100, F(3,13)=$ $.48, p=.700$. The main effects of disability related stressors, $\beta=.023$, s.e. $=.022, p=.305$, and spiritual-centered coping, $\beta=-.004$, s.e. $=.191, p=.983$ were not significant predictors of perceived stress score. The overall interaction effect between disability related stressors and spiritual-centered coping also did not meet statistical significance, $\Delta R^{2}=.023, F(1,13)=.34, p$ $=.572$. For collective coping strategy as a moderator, the overall moderation model fell short of statistical significance, $R^{2}=.158, F(3,12)=.75, p=.543$. The main effects of disability related stressors, $\beta=.021$, s.e. $=.021, p=.349$, and collective coping, $\beta=.231$, s.e. $=.301, p=.458$ were not significant predictors of perceived stress score. The overall interaction effect between disability related stressors and collective coping also did not meet statistical significance, $\Delta R^{2}=$ $.032, F(1,12)=.45, p=.514$ 
Table 6

Moderation Effect of Africultural Coping Strategies on the Relationship between Racial Minority

Student Stress and Perceived Stress Level

\begin{tabular}{|c|c|c|c|c|c|c|}
\hline Variable & $\beta$ & $S E$ & $t$ & $p$ & \multicolumn{2}{|c|}{$95 \% \mathrm{CI}$} \\
\hline \multicolumn{7}{|l|}{ DV: Perceived Stress Level } \\
\hline Racial Minority Student Stress Total (MSS) & .08 & .03 & 3.16 & $.000 * * *$ & .03 & .14 \\
\hline Spiritual-Centered Coping (S-ACSI) & .13 & .25 & .51 & .608 & -.37 & .63 \\
\hline Interaction between MSS and S-ACSI & -.00 & .00 & -.54 & .592 & -.01 & .00 \\
\hline \multicolumn{7}{|l|}{$R=.39, \Delta R^{2}=.002, F(1,113)=.29, p=.592$} \\
\hline \multicolumn{7}{|l|}{ DV: Perceived Stress Level } \\
\hline Racial Minority Student Stress Total (MSS) & .11 & .04 & 2.71 & $.008 * *$ & .03 & .18 \\
\hline Collective Coping (C-ACSI) & .40 & .32 & 1.23 & .221 & -.24 & 1.04 \\
\hline Interaction between MSS and C-ACSI & -.00 & .00 & -1.01 & .314 & -.01 & .00 \\
\hline \multicolumn{7}{|l|}{$R=.41, \Delta R^{2}=.008, F(1,112)=1.02, p=.314$} \\
\hline \multicolumn{7}{|l|}{ DV: Perceived Stress Level } \\
\hline Racial Minority Student Stress Total (MSS) & .07 & .02 & 3.64 & $.000 * * *$ & .03 & .11 \\
\hline Ritual-Centered Coping (R-ACSI) & -.00 & 1.17 & -.00 & .998 & -2.32 & 2.31 \\
\hline Interaction between MSS and R-ACSI & .00 & .01 & .12 & .903 & -.02 & .02 \\
\hline \multicolumn{7}{|l|}{$R=.39, \Delta R^{2}=.000, F(1,114)=.02, p=.903$} \\
\hline \multicolumn{7}{|l|}{ DV: Perceived Stress Level } \\
\hline Racial Minority Student Stress Total (MSS) & .09 & .04 & 2.42 & $.017 *$ & .02 & .16 \\
\hline Cognitive-Emotional Coping (CE-ACSI) & .37 & .18 & 2.01 & $.046^{*}$ & .01 & .74 \\
\hline Interaction between MSS and CE-ACSI & -.00 & .00 & -.95 & .346 & -.01 & .00 \\
\hline$R=.45, \Delta R^{2}=.006, F(1,113)=.90, p=.346$ & & & & & & \\
\hline
\end{tabular}

$* p<.05 . * * p<.01 . * * * p<.001$.

Note: DV= Dependent Variable, ACSI = Africultural Coping System Inventory 
Table 7

Moderation Effect of Africultural Coping Strategies on the Relationship between Disability Related Stress and Perceived Stress Level

\begin{tabular}{|c|c|c|c|c|c|c|}
\hline \multirow{2}{*}{$\begin{array}{l}\text { Variable } \\
\text { DV: Perceived Stress Level }\end{array}$} & \multirow[t]{2}{*}{$\beta$} & \multirow[t]{2}{*}{$S E$} & \multirow[t]{2}{*}{$t$} & \multirow[t]{2}{*}{$p$} & \multicolumn{2}{|c|}{$95 \% \mathrm{CI}$} \\
\hline & & & & & & \\
\hline Disability Related Stress Total (DRSS) & .04 & .04 & .89 & .391 & -.05 & .13 \\
\hline Spiritual-Centered Coping (S-ACSI) & .16 & .31 & .52 & .609 & -.51 & .83 \\
\hline Interaction between MSS and S-ACSI & -.00 & .00 & -.58 & .572 & -.01 & .00 \\
\hline \multicolumn{7}{|l|}{$R=.32, \Delta R^{2}=.023, F(1,13)=.34, p=.572$} \\
\hline \multicolumn{7}{|l|}{ DV: Perceived Stress Level } \\
\hline Disability Related Stress Total (DRSS) & .05 & .06 & .85 & .414 & -.08 & .18 \\
\hline Collective Coping (C-ACSI) & .53 & .53 & .99 & .343 & -.64 & 1.69 \\
\hline Interaction between MSS and C-ACSI & -.00 & .00 & -.67 & .514 & -.01 & .01 \\
\hline \multicolumn{7}{|l|}{$R=.40, \Delta R^{2}=.032, F(1,12)=.45, p=.514$} \\
\hline \multicolumn{7}{|l|}{ DV: Perceived Stress Level } \\
\hline Disability Related Stress Total (DRSS) & .03 & .03 & .99 & .341 & -.03 & .09 \\
\hline Ritual-Centered Coping (R-ACSI) & 1.92 & .66 & 2.90 & $.012 *$ & .49 & 3.35 \\
\hline Interaction between MSS and R-ACSI & -.01 & .00 & -1.47 & .165 & -.02 & .00 \\
\hline \multicolumn{7}{|l|}{$R=.70, \Delta R^{2}=.086, F(1,13)=2.16, p=.165$} \\
\hline \multicolumn{7}{|l|}{ DV: Perceived Stress Level } \\
\hline Disability Related Stress Total (DRSS) & .06 & .06 & .93 & .372 & -.08 & .19 \\
\hline Cognitive-Emotional Coping (CE-ACSI) & .59 & .36 & 1.62 & .129 & -.20 & 1.38 \\
\hline Interaction between MSS and CE-ACSI & -.00 & .00 & -.87 & .402 & -.01 & .00 \\
\hline$R=.51, \Delta R^{2}=.043, F(1,13)=.75, p=.402$ & & & & & & \\
\hline
\end{tabular}

*. $P$ value is significant at .05 level (2- tailed). ${ }^{*} p<.05$ 


\section{Supplementary Analyses}

Additional supplementary moderated regression analyses were conducted with cognitive debriefing and ritual centered coping as moderators for exploratory purposes. Results revealed that ritual-centered coping strategy as a moderator of the relationship between racial minority stressors and perceive stress showed a statistically significant overall moderation model, $R^{2}=$ $.152, F(3,114)=6.81, p<.001$. The main effect of racial minority student stressors on perceive stress was positive and significant, $\beta=.069$, s.e. $=.019, p<.001$, however the main effect of ritual centered coping on perceive stress was negative and not significant, $\beta=-.003$, s.e. $=1.170$, $p=.998$. The overall interaction effect between racial minority student stressors and ritualcentered coping fell short of statistical significance, $\Delta R^{2}=.0001, F(1,114)=.02, p=.903$. For cognitive-emotional debriefing as a moderator of the relationship between racial minority stressors and perceive stress score, the overall model had significant effect of variance in perceived stress score, $R^{2}=.201, F(3,113)=9.47, p<.001$. The main effects of racial minority stressors, $\beta=.086$, s.e. $=.035, p=.017$, and cognitive-emotional debriefing, $\beta=.372$, s.e. $=.185$, $p=.046$ were also positive and significant predictors of perceived stress score. However, given the number of regression analyses repeated, this result should be considered not statistically significant with a more conservative $\mathrm{p}$-value with Bonferroni correction. The overall interaction effect between racial minority student stressors and cognitive-emotional debriefing was not significant, $\Delta R^{2}=.006, F(1,113)=.90, p=.346$.

Another moderated regression analysis using SPSS PROCESS macro was conducted with disability-related stressors as the independent variable, perceived stress as the dependent variable, and ritual-centered and cognitive-emotional debriefing coping strategies as the moderators among the subsample of Black students with disability. For ritual-centered coping 
strategy as a moderator, the overall moderation model had significant effect of variance in perceived stress score, $R^{2}=.483, F(3,13)=4.05, p=.031$. The main effect of disability related stressors, $\beta=.028$, s.e. $=.028, p=.341$ did not meet statistical significance, however, ritualcentered coping, $\beta=1.919$, s.e. $=.661, p=.012$, showed a positive and significant main effect on perceived stress score. The overall interaction effect between disability related stressors and ritual-centered coping was however not significant statistically, $\Delta R^{2}=.086, F(1,13)=2.16, p=$ .165. For cognitive-emotional debriefing as a moderator of the relationship between disability related stressors and perceive stress score, the overall moderation model fell short of statistical significance, $R^{2}=.258, F(3,12)=1.51, p=.259$. The main effects of disability related stressors, $\beta=.057$, s.e. $=.061, p=.372$, and cognitive-emotional debriefing, $\beta=.591$, s.e. $=.365, p=.129$ were not significant predictors of perceived stress score. The overall interaction effect between disability related stressors and cognitive-emotional debriefing also did not meet statistical significance, $\Delta R^{2}=.043, F(1,13)=.75, p=.402$.

\section{Exploratory Question}

\section{Research Question (R1)}

The research question was to explore whether Black American students with disabilities differ from Black American students without disabilities in terms of the type of Africultural coping strategies used in handling stress.

A multivariate ANOVA was conducted with the four Africultural coping strategies as the dependent variables and the disability status as the independent variable. Results indicated a statistical significant difference exist between Black/African Americans with disabilities and Black/African Americans without disabilities when considered jointly on the variables spiritualcentered coping, collective coping, ritual-centered coping and cognitive-emotional debriefing, 
Wilk's $\Lambda=.886, \mathrm{~F}(4,114)=3.68, \mathrm{p}=.007$, partial $\mathrm{p}^{2}=.11$. A separate ANOVA was conducted for each dependent variable, with each ANOVA evaluated at an alpha level of .025. Results revealed there were no significant mean differences between the two groups in the level of coping strategy usage, except for ritual-centered coping, $\mathrm{F}(1,117)=14.64, \mathrm{p}<.001$, partial $\mathrm{y}^{2}=.11$, with Black/African Americans having disabilities (M=1.97) scoring higher than Black/African Americans without disabilities $(\mathrm{M}=.55)$.

Table 8

Sample Descriptive Statics and Multiple Analyses of Variance in Africultural Coping between Black American Students with Disabilities and Black American Students without Disabilities

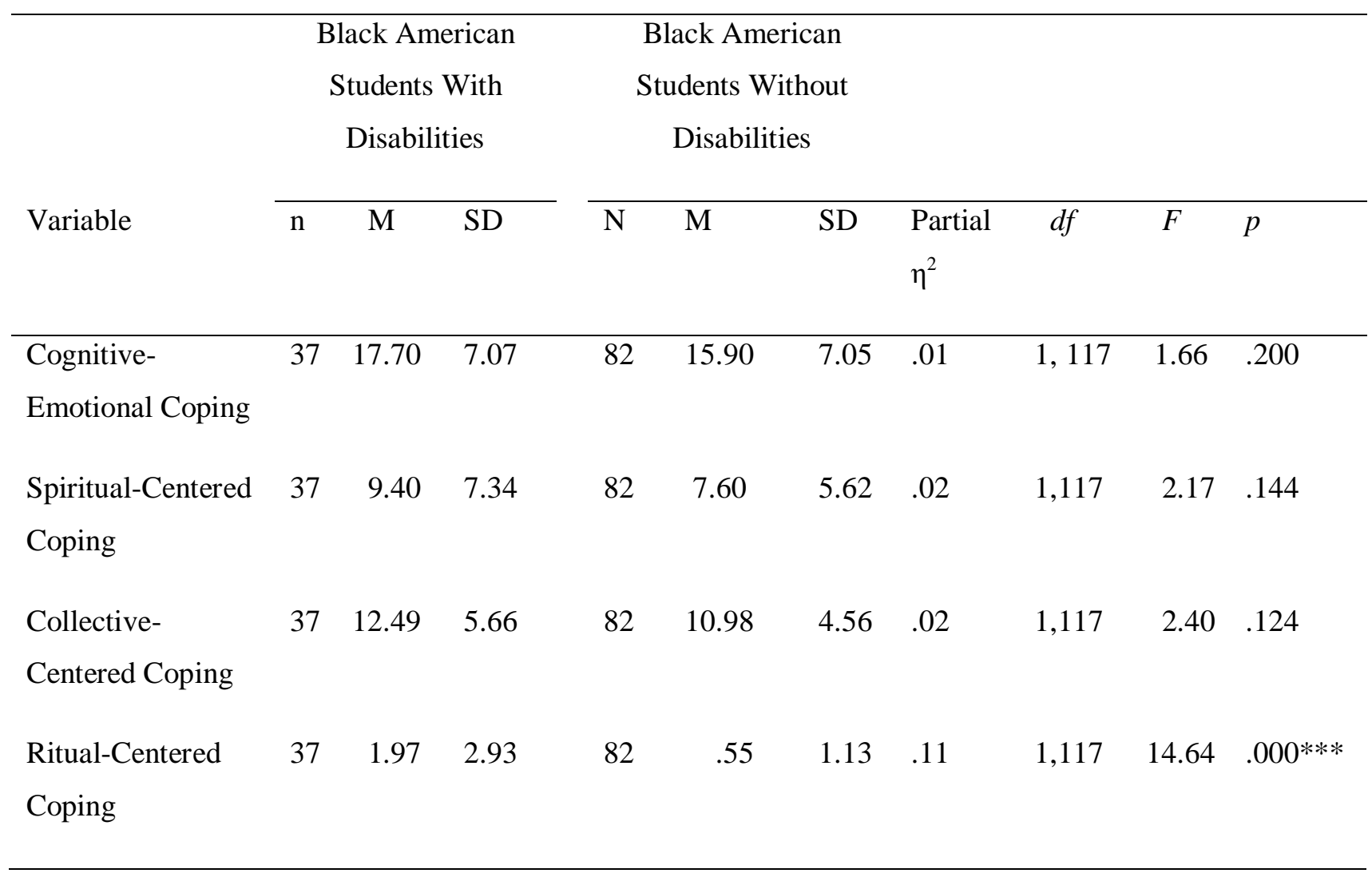

*. $P$ value is significant at .001 level (2- tailed). $* * * p<.001$

Note: $\mathrm{n}=$ Sample Size, $\mathrm{SD}=$ Stand Deviation, $\mathrm{M}=$ Mean 


\section{CHAPTER V: DISCUSSIONS}

\section{Stress Level Related to the Intersectionality of Black Identity and Disability Status}

Although previous research has contributed to elucidating our understanding of the stress experienced by Black/African Americans, little has been written about the differences in stress experienced by Black/African Americans based on their disability status. Through this research study, I sought to address the largely overlooked intersectionality between Black/African American identity and disability and also, to gain a more detailed understanding of differences between this subgroup of Black/African American students in their perceived stress levels.

When comparing Black American students with disabilities to those without disabilities, as predicted in hypothesis 1, Black American students with disabilities reported higher level of perceived stress compared to Black American students without disabilities. Also, racial minority stressors, and the societal barrier subscale scores of disability-related stressors were significantly associated with overall perceived stress, supporting hypothesis 2 . These results support the idea of double jeopardy (Blanchett, Mumford \& Beachum, 2005): the double minoritized identities appear to add up the felt level of stress among Black American students with disabilities.

There are several factors that are related to this double minority status that may cause high perceive stress level. A Black/African American student with disability may have to deal with the frustration of both racism and ableism. An extensive amount of literature has documented racist treatments against Black college students (Steele, 2003; Wei et al., 2012). In addition, disability may increase the likelihood of marginalization within academic environment as people have been shown to react to disability in many stereotypic ways (Bramston \& Fogarty, 2000). The assumption of being less competent, for example, can be falsified by working even harder (Köllen, Halbesleben \& Rose, 2014). That said, if Black American students with 
disabilities permanently have to work harder merely in order discredit certain persistent stereotype without receiving other kinds of additional resources that exceed the compensation less hard-working colleagues without disabilities receive; this might actually lead to strong feelings of unfair treatment which they might attribute to their racial minority status. Perhaps, high identification with being Black/African American increase sensitivity to disability related stressors. Another possibility is that Black/African American students with disability who have high ethnic minority identity may be likely to openly confront a system that they perceive as discriminatory and this openness may contribute to a backlash leading to high racial minority stress. In fact, research has shown that Black/African Americans with disabilities are prone to experience discrimination and harassment (Blanchett, Mumford, \& Beachum, 2005; Prince, Patel, Saxena, et al., 2007). Having two minoritized status could double up the chance of experiencing biased treatments, resulting in higher level of felt stress.

Second, their double minoritized status may limit the support from campus, exacerbating the felt stress. Particularly on a predominantly White campus, students would have fewer opportunities for cultural validation for their Black / African American identity and that can add more stress (Harrell, 2000; Johnson - Ahorlu, 2013). Coupled with cultural mistrust (Whaley, 2001) in the mainstream institutions and services, Black American students with disabilities may feel more hesitant with seeking accommodation services and resources from campus disability offices. This continued higher level of stress coupled with less support and resources would be detrimental to these students. They could undermine academic performance, which in turn reinforce negative feeling of self and abilities to succeed in the college environment (Cokley et al., 2013) and undermine mental well-being of these students (Browman et al., 2000; Kwate et al., 2003; Laurence, Williams, \& Eiland, 2009). 


\section{Africultural Coping Not Buffering Minority Stress on Felt Stress}

It is essential to identify ways of addressing the higher level of stress among Black American students. While efforts for system-level changes to address the interpersonal and institutional racism and ableism takes time, Black students, particularly those with disabilities, need to cope with the stressors on a daily basis to reduce stress, survive and thrive on college campus. I hypothesized that, among others, Africultural coping strategies would moderate the relationships between minority stressors (racial minority student stress and disability related stress) and perceived stress levels for Black/African Americans. I chose Africultural coping as more effective coping options over general coping because of its relevance to and validation of their Black/African American culture. Contrary to the prediction, the result revealed no significant interaction for minority stressors and Africultural coping in predicting perceived stress. It is possible that Africultural coping efforts, although students would resort to them, may not be enough in reducing the felt stress when they encounter racial and disability-related stressors. This result suggests the need to identify other internal resources that could help Black students with and without disabilities. More importantly, this result attests to the importance of addressing system level, institutional level barriers and oppressions related to race and disability.

Examination of each of the four Africultural coping strategies revealed some more unexpected findings. First, higher use of cognitive-emotional debriefing coping rather increased perceived stress associated with racial minority student stress. Although the finding may not be significant when a conservative $\mathrm{p}$-value is applied, similar mixed findings for the role of cognitive-emotional debriefing have been observed in previous studies. Thomas et al. (2008) found cognitive-emotional debriefing to have negative consequences for Black/African Americans, explaining the positive relationship found between gendered racism and 
psychological distress was partially mediated by Cognitive-emotional debriefing; however, they found no mediation for spiritual-centered coping, collective-coping, and ritual-centered efforts. Greer (2011) however found cognitive-emotional debriefing to have inverse effect in the relationship between race-related stress and mental health symptoms for African American women. Thus, as cognitive-emotional debriefing coping efforts increased, anxiety symptoms decreased (Greer, 2011).

Also, ritual - centered coping showed a positive main effect; it was associated with increased level of perceived stress in the context of disability related stress. This unexpected result may be consistent with the previous suggestions that religious/spiritual coping can be challenging and anxiety provoking for some people because it is letting go of personal control to Higher Power (Hunn \& Graig, 2009), and therefore in a sense giving up your own control. Previous research has shown that a sense of control over stressors is essential in maintaining mental health and emotional well-being (Keeton, Perry-Jenkins \& Sayer, 2008). In fact, Cole and Pargament (1999) reported that the process of surrendering personal control to higher or mystical powers could be very challenging for some Black/African Americans. This is also consistent with previous finding that some coping strategies may not only be ineffective but also increase level of felt stress (Bland et al., 2012).

This study also revealed not only no interaction (i.e., protective) effect but also no main effect of spiritual-centered and collective - centered coping on perceived stress level. In fact, previous research findings are mixed. For example, Greer (2011) revealed similar results for no main effect of spiritual centered and collective - centered coping on stress. On the other hand, some studies reported the advantages of using spiritual-centered and collective-centered coping to address problems that occur in the lives of Black/African Americans (Mattis, 2002; Utsey, 
Adams, et al., 2000; Utsey et al., 2007). Daly, Jennings, Beckett, and Leashore (1995) suggested that multiple coping efforts are needed for managing high levels of stress caused by unique racerelated stressors. It is possible that Black American students may engage in other coping strategies (i.e. exercise, yoga, etc.). It is also possible that they may engage in these coping efforts, but they may not be sufficient or effective enough in reducing felt stress for African American students.

Furthermore, research suggests academia embraces a sense of independence rather than dependence on religion (Cherry, Deberg, \& Porterfield, 2001). Since the mainstream American culture advocates a stance of independence (Uchida et al., 2008) there is a possibility that the Black/African American university student participants may be less prone to turning to a religious deity or collective coping. Perhaps as the Black American students becomes more acculturated to the majority White culture at PWI's, they are becoming less grounded in their roots than they were in the past and therefore they use spiritual and collective coping less often when confronted with stress. Thus, further research may warrant an exploration of factors that influence shift in tendency away from the hypothesized use of spiritual and collective-centered coping.

\section{Africultural Coping Strategy and Disability Status}

One interesting finding was that the Black American students with disabilities used more ritual-centered coping strategies compared with those with no disabilities. Ritual-centered coping efforts, according to Utsey et al. (2000), entail burning incense or lighting candles for guidance and the belief in the mystical powers of religious symbols (e.g., cross) to address problems. In other words, this is not a coping that addresses the problem directly (i.e., problem-focused coping from the traditional coping framework). Reliance on rituals further entails acceptance of 
the limits of one's control or personal power in mitigating difficulties (Cole \& Pargament, 1999). It is possible that double minoritized status-related stressors may be perceived as something that they cannot change or control, due to repeated marginalizing and oppressive experiences. Therefore, it is plausible that, whenever these students appraise themselves as having less control about the stressors, they encounter in the university environment, the process of engaging in rituals-centered coping evoked spiritual beliefs that such activities could mitigate their experience of minority stressors.

\section{Limitations and Strengths}

There are several limitations of this study. First, this study utilized correlational analysis; we cannot infer establishing true cause-and-effect relationships. Second, this sample consisted of Black/African American students studying in the Mid-Western regions of United States of America, which limits our understanding of this topic with Black/African American college students attending PWIs in other geographic regions of the United States, or non-PWIs. Another limitation to this study is a retrospective self-report account used in this study. The use of selfreport data for Africultural coping has been noted as an obstacle in previous research because research participants may inaccurately remember the events in question, participants are sometimes unable to recollect how they responded to the event, or they exaggerate their response to the event (Utsey, Adams et al., 2000). The last one to mention is the small sample size of the Black American students with disability. It was enough to detect interactions for moderate effect size but insufficient to detect interactions for a small effect size.

Despite these limitations, this study has several strengths worth noting. To the best of my knowledge, this is the first quantitative study to explore the relationship between minority stressors (racial minority student stress, disability related stress) and perceive stress level among 
Black/African American students with and without disabilities attending PWIs. Also, this research explored the moderating effect of Africultural coping strategies on the relationship between minority stressors (racial minority stress, disability related stress) and perceived stress level, which may increase our understanding on effective ways Black/African American university students especially those with disabilities may manage stressors experienced on predominately White university campuses. Also, findings draw attention to the potential negative effects that minority stressors may have on the mental health outcomes of Black American students at PWIs.

\section{Future Directions and Implications}

The research results showed that ritual-centered coping contributed in the increase of perceive stress level among the Black American students. Future studies should clarify the meaning of this finding. For example, researchers could consider using multimethod strategies (e.g. daily records, observer reports from participants' peers etc) in assessing Africultural coping strategies. It is possible that ritual-centered coping may be something students engage in to validate their cultural ground in face of oppressions, although it does not reduce felt stress necessarily.

Given the significant difference in perceive stress level for Black/African American students with and without disabilities in the current research, there is the need for more tailored intervention efforts aiming to reduce felt stress for Black/African American students. Since previous literature contends Black/African Americans are reluctant to seek out psychological services (Masuda et al., 2009; Whaley et al., 2002), if Black/African American students does seek these services, it will be important to explore and address what role (if any) minority status 
stressors (racial minority stress, disability related stress) play in their presenting concerns so that they could benefit and see mental health services as effective.

Also, accommodation offices on campus should be mindful of Black students' cultural mistrust and make culturally sensitive efforts in offering their services for Black students with disabilities. University staffs and faculty trainings that pays particular attention to cultural competency development and cultural awareness unique to the experiences of Black American students especially those with disabilities is warranted to foster a safe and supportive learning environment. 


\section{REFERENCES}

American College Health Association. (2013). National college health assessment: Reference group executive summary report. Retrieved from http://www.achancha.org/reports_ACHA-NCHAII.html

American Psychological Association, \& American Psychological Association. (2016). Stress in America: The impact of discrimination. Stress in America Survey, 2016.

Ancis, J. R., Sedlacek, W. E., \& Mohr, J. J. (2000). Student perceptions of campus cultural climate by race. Journal of Counseling \& Development, 78(2), 180-185.

Andersson, G., \& Hägnebo, C. (2003). Hearing impairment, coping strategies, and anxiety sensitivity. Journal of Clinical Psychology in Medical Settings, 10(1), 35-39.

Andrews, B., \& Wilding, J. M. (2004). The relation of depression and anxiety to life-stress and achievement in students. British journal of psychology, 95(4), 509-521.

Aranda, E., \& Rebollo-Gil, G. (2004). Ethnoracism and the "sandwiched" minorities. American Behavioral Scientist, 47(7), 910-927.

Arbona, C., \& Nora, A. (2007). The influence of academic and environmental factors on Hispanic college degree attainment. The Review of Higher Education, 30(3), 247-269.

Arthur, C. M. (2007). A little rain each day: Psychological stress \& health disparities. Californian Journal of Health Promotion, 43, 558-67.

Asbury, C. A. (1991). Disability Prevalence and Demographic Association among Race/Ethnic Minority Populations in the United States: Implications for the 21st Century. Monograph Series Number Two. 
Austin, C. C., Clark, E. M., Ross, M. J., \& Taylor, M. J. (2009). Impostorism as a mediator between survivor guilt and depression in a sample of African American college students. College Student Journal, 43(4).

Bacchus, D. N. (2008). Coping with work-related stress: A study of the use of coping resources among professional Black women. Journal of Ethnic \& Cultural Diversity in Social Work, 17(1), 60-81.

Balcazar, F. E., Suarez-Balcazar, Y., Adames, S. B., Keys, C. B., García-Ramírez, M., \& Paloma, V. (2012). A case study of liberation among Latino immigrant families who have children with disabilities. American Journal of Community Psychology, 49(1-2), 283-293.

Baldwin, D. R., Towler, K., Oliver, M. D., \& Datta, S. (2017). An examination of college student wellness: A research and liberal arts perspective. Health psychology open, 4(2), 2055102917719563.

Banks, J., \& Hughes, M. S. (2013). Double consciousness: Postsecondary experiences of African American males with disabilities. The Journal of Negro Education, 82(4), 368-381

Belgrave, F. Z. (1998). Psychosocial aspects of chronic illness and disability among African Americans. Greenwood Publishing Group.

Blanchett, W. J., Mumford, V., \& Beachum, F. (2005). Urban school failure and disproportionality in a post-Brown era: Benign neglect of the constitutional rights of students of color. Remedial and Special Education, 26(2), 70-81.

Bland, H. W., Melton, B. F., Welle, P., \& Bigham, L. (2012). Stress tolerance: New challenges for millennial college students. College Student Journal, 46(2), 362-376. 
Blick, R. N., Saad, A. E., Goreczny, A. J., Roman, K., \& Sorensen, C. H. (2015). Effects of declared levels of physical activity on quality of life of individuals with intellectual disabilities. Research in developmental disabilities, 37, 223-229.

Bowen Reid, T. L., \& Smalls, C. (2004). Stress, Spirituality and Health Promoting Behaviors Among African American College Students. Western Journal of Black Studies, 28(1).

Bramston, P., \& Fogarty, G. (2000). The assessment of emotional distress experienced by people with an intellectual disability: a study of different methodologies. Research in Developmental Disabilities, 21(6), 487-500.

Broman, C. L., Mavaddat, R., \& Hsu, S. (2000). The experience and consequences of perceived racial discrimination: A study of African Americans. Journal of Black Psychology, 26(2), 165-180. doi: http://dx.doi.org/10.1177/0095798400026002003.

Bruininks, R. H., Keeney, B., \& Thorp, J. (2010). Transforming America's universities to compete in the "new normal". Innovative Higher Education, 35(2), 113-125. doi: $10.1007 / \mathrm{s} 10755-009-9135$.

Carter, R. T. (2007). Racism and psychological and emotional injury: Recognizing and assessing race-based traumatic stress. The Counseling Psychologist, 35(1), 13-105. doi: 10.1177/0011000006292033.

Carver, C. S., Scheier, M. F., \& Weintraub, J. K. (1989). Assessing coping strategies: a theoretically based approach. Journal of personality and social psychology, 56(2), 267.

Cherry, C., \& Deberg, B. A. A. Porterfield. 2001. Religion on campus.

Chrisman, S. M., Pieper, W. A., Clance, P. R., Holland, C. L., \& Glickauf-Hughes, C. (1995). Validation of the Clance imposter phenomenon scale. Journal of Personality Assessment, $65(3), 456-467$. 
Clance, P. R. (1985). The impostor phenomenon: Overcoming the fear that haunts your success. Atlanta, GA: Peachtree.

Clark, R., Anderson, N. B., Clark, V. R., \& Williams, D. R. (1999). Racism as a stressor for African Americans: A biopsychosocial model. American psychologist, 54(10), 805.

Cohen, S., Kamarck, T., \& Mermelstein, R. (1983). A global measure of perceived stress. Journal of health and social behavior, 385-396.

Cokley, K., McClain, S., Enciso, A., \& Martinez, M. (2013). An examination of the impact of minority status stress and impostor feelings on the mental health of diverse ethnic minority college students. Journal of Multicultural Counseling and Development, 41(2), $82-95$.

Cole, B., \& Pargament, K. (1999). Spiritual surrender: A paradoxical path to control. In W. Miller (Ed.), Integrating spirituality into treatment: Resources for practitioners (pp. 179198). Washington, DC: American Psychological Association.

Cole, E. R. (2009). Intersectionality and research in psychology. American psychologist, 64(3), 170.

Crisp R. (2002). A Counselling Framework for Understanding Individual Experiences of Socially Constructed Disability. Disability Studies Quarterly. 22: 20-32.

Crouch, R., Keys, C. B., \& McMahon, S. D. (2014). Student-teacher relationships matter for school inclusion: School belonging, disability, and school transitions. Journal of prevention \& intervention in the community, 42(1), 20-30.

Daly, A., Jennings, J., Beckett, J. O., \& Leashore, B. R. (1995). Effective coping strategies of African Americans. Social Work, 40, 240-248.

Dohrenwend B.P. Adversity, stress, and psychopathology. New York: Oxford University Press; $1998 \mathrm{a}$ 
Dohrenwend, B. P. (2000). The role of adversity and stress in psychopathology: Some evidence and its implications for theory and research. Journal of health and social behavior, 1-19.

Drum, C. E., Krahn, G., Culley, C., \& Hammond, L. (2005). Recognizing and responding to the health disparities of people with disabilities. Californian Journal of Health Promotion, $3(3), 29-42$.

Dusselier, L., Dunn, B., Wang, Y., Shelley iI, M. C., \& Whalen, D. F. (2005). Personal, health, academic, and environmental predictors of stress for residence hall students. Journal of American college health, 54(1), 15-24.

Dyson, R., \& Renk, K. (2006). Freshmen adaptation to university life: Depressive symptoms, stress, and coping. Journal of clinical psychology, 62(10), 1231-1244.

Eisenberg, D., Gollust, S. E., Golberstein, E., \& Hefner, J. L. (2007). Prevalence and correlates of depression, anxiety, and suicidality among university students. American journal of orthopsychiatry, 77(4), 534-542.

Esses, V. M., \& Beaufoy, S. L. (1994). Determinants of attitudes toward people with disabilities. Journal of Social Behavior and Personality, 9, 43-64. Fine, M.

Esia-Donkoh, K., Yelkpieri, D., \& Esia-Donkoh, K. (2011). Coping with Stress: Strategies Adopted by Students at the Winneba Campus of University of Education, Winneba, Ghana. Online Submission.

Firth, N., Frydenberg, E., \& Greaves, D. (2008). Perceived control and adaptive coping: Programs for adolescent students who have learning disabilities. Learning Disability Quarterly, 31(3), 151-165.

Folkman, S., \& Lazarus, R. S. (1990). Coping and emotion. Psychological and biological approaches to emotion, 313-332. 
Folkman, S., Lazarus, R. S., Dunkel-Schetter, C., DeLongis, A., \& Gruen, R. J. (1986).

Dynamics of a stressful encounter: cognitive appraisal, coping, and encounter outcomes. Journal of personality and social psychology, 50(5), 992.

Forbus, P., Newbold, J. J., \& Mehta, S. S. (2011). A study of non-traditional and traditional students in terms of their time management behaviors, stress factors, and coping strategies. Academy of Educational Leadership Journal, 15, 109.

Friedlander, L. J., Reid, G. J., Shupak, N., \& Cribbie, R. (2007). Social support, self-esteem, and stress as predictors of adjustment to university among first-year undergraduates. Journal of College Student Development, 48(3), 259-274.

Fuller-Thomson, E., \& Brennenstuhl, S. (2012). People with disabilities: the forgotten victims of violence. The Lancet, 379(9826), 1573-1574.

Galaif, E. R., Sussman, S., Chou, C. P., \& Wills, T. A. (2003). Longitudinal relations among depression, stress, and coping in high-risk youth. Journal of youth and adolescence, $32(4), 243-258$.

Gonzalez JM, Alegria M, Prihoda TJ, Copeland LA, Zeber JE. How the relationship of attitudes toward mental health treatment and service use differs by age, gender, ethnicity/race, and education. Social Psychiatry and Psychiatric Epidemiology. 2009 doi: 10.1007/s00127009-0168-4.

Gorman, J. C. (1999). Understanding Childrens Hearts and Minds: Emotional Functioning and Learning Disabilities. Teaching exceptional children, 31(3), 72-77.

Graham, B. C., Keys, C. B., McMahon, S. D., \& Brubacher, M. R. (2014). Transportation challenges for urban students with disabilities: Parent perspectives. Journal of prevention \& intervention in the community, 42(1), 45-57. 
Greaves, D., Greaves, D., \& Jeffery, P. (1998). Learning disabled children coping with challenging academic tasks. Strategies for intervention with special needs students, 63-74.

Greer, T. M. (2011). Coping strategies as moderators of the relationship between race-and gender-based discrimination and psychological symptoms for African American women. Journal of Black Psychology, 37(1), 42-54.

Greer, T. M., \& Brown, P. (2011). Minority status stress and coping processes among African American college students. Journal of Diversity in Higher Education, 4(1), 26.

Greer, T. M. \& Chwalisz, K. (2007). Minority-Related Stressors and Coping Processes Among African American College Students. Journal of College Student Development 48(4), 388404. Johns Hopkins University Press. Retrieved June 18, 2019, from Project MUSE database.

Greer, T. M., Ricks, J., \& Baylor, A. A. (2015). The moderating role of coping strategies in understanding the effects of intragroup race-related stressors on academic performance and overall levels of perceived stress for African American students. Journal of Black Psychology, 41(6), 565-585.

Guthman, J. C., Iocin, L., \& Konstas, D. D. (2010, August). Increase in severity of mental illness among clinical college students: A 12-year comparison. In American Psychological Association 118th Annual Convention in San Diego, California.

Harrell, S. P. (2000). A multidimensional conceptualization of racism-related stress: Implications for the well-being of people of color. American Journal of Orthopsychiatry, 70, 42-57. 
Heiman, T. (2004). Teachers Coping with Changes: Including Students with Disabilities in Mainstream Classes: An International View. International journal of special education, 19(2), 91-103.

Holmes, E. P., \& River, L. P. (1998). Individual strategies for coping with the stigma of severe mental illness. Cognitive and Behavioral Practice, 5(2), 231-239.

Hughes, L. A., Banks, P., \& Terras, M. M. (2013). Secondary school transition for children with special educational needs: a literature review. Support for Learning, 28(1), 24-34.

Hystad, S. W., Eid, J., Laberg, J. C., Johnsen, B. H., \& Bartone, P. T. (2009). Academic stress and health: Exploring the moderating role of personality hardiness. Scandinavian Journal of Educational Research, 53(5), 421-429.

Jackson, A. P., \& Sears, S. J. (1992). Implications of an Africentric worldview in reducing stress for African American women. Journal of Counseling \& Development, 71(2), 184-190.

Johnson-Ahorlu, R. N. (2013). Our biggest challenge is stereotypes: understanding stereotype threat and the academic experiences of African American undergraduates. Journal Of Negro Education, 82(4), 382-392.

Kaufman, J. (2006). Stress and social support among online doctoral psychology students. Journal of College Student Psychotherapy, 20,79-88. doi:10.1300/J035v20n03_07.

Keeton, C. P., Perry-Jenkins, M., \& Sayer, A. G. (2008). Sense of control predicts depressive and anxious symptoms across the transition to parenthood. Journal of family psychology, $22(2), 212$.

Killen, M., Rutland, A., \& Yip, T. (2016). Equity and justice in developmental science: Discrimination, social exclusion, and intergroup attitudes. Child development, 87(5), 1317-1336. 
Köllen, T. (2014). A Review of Minority Stress Related to Employees' Demographics and the Development of an Intersectional Framework for Their Coping Strategies in the Workplace. In The Role of Demographics in Occupational Stress and Well Being (pp. 4182). Emerald Group Publishing Limited.

Kohler Giancola, J., Grawitch, M. J., \& Borchert, D. (2009). Dealing with the stress of college: A model for adult students. Adult Education Quarterly, 59(3), 246-263.

Kohn-Wood, L.P., Powell, W. H., Haynes, T., Ferguson, K. K., Jackson, B. A. (2012). Coping styles, depressive symptoms, and race during the transition to adulthood. Mental Health Religion and Culture, 15, 363-372.

Krantz, D. S., \& McCeney, M. K. (2002). Effects of psychological and social factors on organic disease: a critical assessment of research on coronary heart disease. Annual review of psychology, 53(1), 341-369.

Kraus, L., Lauer, E., Coleman, R., and Houtenville, A. (2018). 2017 Disability Statistics Annual Report. Durham, NH: University of New Hampshire.

Kwate, N. O. A., Valdimarsdottir, H. B., Guevarra, J. S., \& Bovbjerg, D. H. (2003). Experiences of racist events are associated with negative health consequences for African American women. Journal of the National Medical Association, 95(6), 450.

Landrine, H., Klonoff, E. A., Corral, I., Fernandez, S., \& Roesch, S. (2006). Conceptualizing and measuring ethnic discrimination in health research. Journal of behavioral medicine, 29(1), 79.

Laurence, B., Williams, C., \& Eiland, D. (2009). Depressive symptoms, stress, and social support among dental students at a historically black college and university. Journal of American College Health, 58(1), 56-63. 
Lazarus, R. S. (1999). Hope: An emotion and a vital coping resource against despair. Social Research, 653-678.

Lazarus, R. S., \& Cohen, J. B. (1977). Environmental stress. In Human behavior and environment (pp. 89-127). Springer, Boston, MA.

Lazarus, R. S., \& Folkman, S. (1984). Stress, appraisal, and coping. Springer publishing company.

Lenz, S. (2010). Exploring College Students' Perception of the Effectiveness of Their Coping Styles for Dealing with Stress. LOGOS: A Journal of Undergraduate Research, 3.

Livneh, H., \& Wilson, L. M. (2003). Coping strategies as predictors and mediators of disabilityrelated variables and psychosocial adaptation: An exploratory investigation. Rehabilitation Counseling Bulletin, 46(4), 194-208.

Magaña, S., Parish, S. L., Rose, R. A., Timberlake, M., \& Swaine, J. G. (2012). Racial and ethnic disparities in quality of health care among children with autism and other developmental disabilities. Intellectual and developmental disabilities, 50(4), 287-299.

Majer, J. M. (2009). Self-efficacy and academic success among ethnically diverse firstgeneration community college students. Journal of Diversity in Higher Education, 2(4), 243.

Mattis, J. S. (2002). Religion and spirituality in the meaning-making and coping experiences of African American women: A qualitative analysis. Psychology of Women Quarterly, 26, 309-321.

McDonald, K. E., Keys, C. B., \& Balcazar, F. E. (2007). Disability, race/ethnicity, and gender: themes of cultural oppression, acts of individual resistance. American Journal of Community Psychology, 39(1-2), 145-161. 
McNeil, J. M. (1993). Americans with Disabilities, 1991-92. US Department of Commerce, Economics and Statistics Administration, Bureau of the Census.

Meyer, I. H., \& Frost, D. M. (2013). Minority stress and the health of sexual minorities. Handbook of psychology and sexual orientation, 252-266.

Meyer, I. H., \& Northridge, M. E. (Eds.). (2007). The health of sexual minorities: Public health perspectives on lesbian, gay, bisexual and transgender populations. Springer Science \& Business Media.

Murphy, C. G., \& Hicks, T. (2006). Academic Characteristics among First-Generation and NonFirst-Generation College Students. College Quarterly, 9(2), n2.

Murray, C. J., Lopez, A. D., \& World Health Organization. (1996). The global burden of disease: a comprehensive assessment of mortality and disability from diseases, injuries, and risk factors in 1990 and projected to 2020: summary. World Health Organization.

Museus, S. D., \& Quaye, S. J. (2009). Toward an intercultural perspective of racial and ethnic minority college student persistence. The Review of Higher Education, 33(1), 67-94.

Musu-Gillette, L., Robinson, J., McFarland, J., KewalRamani, A., Zhang, A., \& WilkinsonFlicker, S. (2016). Status and Trends in the Education of Racial and Ethnic Groups 2016. NCES 2016-007. National Center for Education Statistics.

Newman, L., Wagner, M., Cameto, R., \& Knokey, A.-M. (2009). The post-high school outcomes of youth with disabilities up to 4 years after high school: A report of findings from the National Longitudinal Transition Study-2 (NLTS2; NCSER 2009-3017). U.S. Department of Education. Menlo Park, CA: SRI International. 
Newman, L., Wagner, M., Knokey, A. M., Marder, C., Nagle, K., Shaver, D., \& Wei, X. (2011). The Post-High School Outcomes of Young Adults with Disabilities up to 8 Years after High School: A Report from the National Longitudinal Transition Study-2 (NLTS2). NCSER 2011-3005. National Center for Special Education Research.

Olié, E., Guillaume, S., Jaussent, I., Courtet, P., \& Jollant, F. (2010). Higher psychological pain during a major depressive episode may be a factor of vulnerability to suicidal ideation and act. Journal of Affective Disorders, 120(1-3), 226-230.

Parish, S., Magaña, S., Rose, R., Timberlake, M., \& Swaine, J. G. (2012). Health care of Latino children with autism and other developmental disabilities: Quality of provider interaction mediates utilization. American Journal on Intellectual and Developmental Disabilities, $117(4), 304-315$.

Phinney, J. S., \& Hass, K. (2003). The process of coping among ethnic minority first Generation college freshman; A narrative approach. Journal of social psychology 143 (6), 707-727.

Pieterse, A. L., \& Carter, R. T. (2007). An examination of the relationship between general life stress, racism-related stress, and psychological health among black men. Journal of Counseling Psychology, 54(1), 101.

Pollock, E. D., Kazman, J. B., \& Deuster, P. (2015). Family functioning and stress in African American families: A strength-based approach. Journal of Black Psychology, 41(2), 144169.

Prince M, Patel V, Saxena S, Maj M, Maselko J, Phillips MR, Rahman (2007) No health without mental health. The Lancet, 370: 859-877

Reid, L. D., \& Radhakrishnan, P. (2003). Race matters: The relation between race and general campus climate. Cultural diversity and ethnic minority psychology, 9(3), 263. 
Reynolds, A. L., Sneva, J. N., \& Beehler, G. P. (2010). The influence of racism-related stress on the academic motivation of Black and Latino/a students. Journal of college student development, 51(2), 135-149.

Rhode, P. C., Froehlich-Grobe, K., Hockemeyer, J. R., Carlson, J. A., \& Lee, J. (2012). Assessing stress in disability: Developing and piloting the Disability Related Stress Scale. Disability and health journal, 5(3), 168-176.

Roberts, A. L., Gilman, S. E., Breslau, J., Breslau, N., \& Koenen, K. C. (2011). Race/ethnic differences in exposure to traumatic events, development of post-traumatic stress disorder, and treatment-seeking for post-traumatic stress disorder in the United States. Psychological medicine, 41(1), 71-83.

Robotham, D., \& Julian, C. (2006). Stress and the higher education student: a critical review of the literature. Journal of further and higher education, 30(02), 107-117.

R. Williams, D., \& Williams-Morris, R. (2000). Racism and mental health: The African American experience. Ethnicity \& health, 5(3-4), 243-268.

Salami, T. K., \& Walker, R. L. (2014). Socioeconomic status and symptoms of depression and anxiety in African American college students: The mediating role of hopelessness. Journal of black psychology, 40(3), 275-290.

Salas, A., Carracedo, Á., Richards, M., \& Macaulay, V. (2005). Charting the ancestry of African Americans. The American Journal of Human Genetics, 77(4), 676-680. Journal of Applied Social Psychology, 36(5), 1198-1214.

Sanders Thompson, V. L. (2006). Coping Responses and the Experience of Discrimination 1. Journal of Applied Social Psychology, 36(5), 1198-1214. 
Siegel, K., Anderman, S. J., \& Schrimshaw, E. W. (2001). Religion and coping with healthrelated stress. Psychology and Health, 16(6), 631-653.

Smedley, B. D., Myers, H. F., \& Harrell, S. P. (1993). Minority-status stresses and the college adjustment of ethnic minority freshmen. The Journal of Higher Education, 64(4), 434452.

Spencer, M. B., Fegley, S. G., \& Harpalani, V. (2003). A theoretical and empirical examination of identity as coping: Linking coping resources to the self processes of African American youth. Applied Developmental Science, 7(3), 181-188.

Steele, C. (2003). Stereotype threat and African American student achievement. The inequality reader: Contemporary and foundational readings in race, class, and gender, 276-281.

Struthers, C. W., Perry, R. P., \& Menec, V. H. (2000). An examination of the relationship among academic stress, coping, motivation, and performance in college. Research in higher education, 41(5), 581-592.

Sue, D. W., Capodilupo, C. M., Torino, G. C., Bucceri, J. M., Holder, A., Nadal, K. L., \& Esquilin, M. (2007). Racial microaggressions in everyday life: implications for clinical practice. American psychologist, 62(4), 271.

Swim, J. K., Hyers, L. L., Cohen, L. L., Fitzgerald, D. C., \& Bylsma, W. H.(2003). African American college students' experiences with everydayracism: Characteristics of and responses to these incidents.Journal ofBlack Psychology, 29,38-67.

Thomas, A.,Witherspoon, K. M., \& Speight, S. L. (2008). Gendered racism, psychological distress, and coping styles of African American women. Cultural Diversity and Ethnic Minority Psychology, 14, 307-314. 
Tugade, M. M., Fredrickson, B. L., \& Feldman Barrett, L. (2004). Psychological resilience and positive emotional granularity: Examining the benefits of positive emotions on coping and health. Journal of personality, 72(6), 1161-1190.

Turner, F. D., \& Smith, J. K. (2015). A comparative study on the stress levels of black, white, Asian, and Latino undergraduate students. Journal of Research Initiatives, 1(3), 6.

Uchida, Y., Kitayama, S., Mesquita, B., Reyes, J. A. S., \& Morling, B. (2008). Is perceived emotional support beneficial? Well-being and health in independent and interdependent cultures. Personality and social psychology bulletin, 34(6), 741-754

U.S. Department of Health and Human Services Office of Minority Health. Assuring health equity for minority persons with disabilities.http://minorityhealth.hhs.gov/. Published July, 2011. Accessed May 08, 2019.

Utsey, S. O., Adams, E. P., \& Bolden, M. (2000). Development and initial validation of the Africultural Coping Systems Inventory. Journal of Black Psychology, 26(2), 194-215.

Utsey, S. O., Bolden, M. A., Lanier, Y., \& Williams III, O. (2007). Examining the role of culture-specific coping as a predictor of resilient outcomes in African Americans from high-risk urban communities. Journal of Black Psychology, 33(1), 75-93.

Utsey, S. O., Ponterotto, J. G., Reynolds, A. L., \& Cancelli, A. A. (2000). Racial discrimination, coping, life satisfaction, and self-esteem among African Americans. Journal of Counseling \& Development, 78(1), 72-80.

Wang, P. S., Berglund, P., Olfson, M., Pincus, H. A., Wells, K. B., \& Kessler, R. C. (2005). Failure and delay in initial treatment contact after first onset of mental disorders in the National Comorbidity Survey Replication. Archives of general psychiatry, 62(6), 603613. 
Wei, M., Ku, T. Y., \& Liao, K. Y. H. (2011). Minority stress and college persistence attitudes among African American, Asian American, and Latino students: Perception of university environment as a mediator. Cultural Diversity and Ethnic Minority Psychology, 17(2), 195.

Wei, Thomas E. 2012. "Sticks, Stones, Words, and Broken Bones: New Field and Lab Evidence on Stereotype Threat.” Educational Evaluation and Policy Analysis 34(4):465-88.

Welle, P. D., \& Graf, H. M. (2011). Effective lifestyle habits and coping strategies for stress tolerance among college students. American Journal of Health Education, 42(2), 96-105.

Whaley, A. L. (2001). Cultural mistrust: An important psychological construct for diagnosis and treatment of African Americans. Professional Psychology: Research and Practice, 32(6), 555.

Williams, D. R., \& Jackson, P. B. (2005). Social sources of racial disparities in health. Health affairs, 24(2), 325-334.

World Health Organization. (2010). Disability assessment schedule II (WHODAS II) 2001. World Health Organization. (2000). WHODAS II-Disability Assessment Schedule Training Manual: A guide to administration. Geneva: World Health Organization.

Young, J. L., Griffith, E. E., \& Williams, D. R. (2003). The integral role of pastoral counseling by African American clergy in community mental health. Psychiatric Services, 54(5), 688-692.

Zajacova, A., Lynch, S. M., \& Espenshade, T. J. (2005). Self-efficacy, stress, and academic success in college. Research in higher education, 46(6), 677-706.

Zautra, A. J., \& Manne, S. L. (1992). Coping with rheumatoid arthritis: A review of a decade of research. Annals of behavioral medicine, 14(1), 31-39. 
Zea, M. C., Belgrave, F. Z., Townsend, T. G., Jarama, S. L., \& Banks, S. R. (1996). The influence of social support and active coping on depression among African Americans and Latinos with disabilities. Rehabilitation Psychology, 41(3), 225.

Zeidner, M., \& Saklofske, D. (1996). Adaptive and maladaptive coping. 


\section{APPENDIX A: DEMOGRAPHIC INFORMATION}

(Please check all that apply)

1. Gender:

Female Male Transgender

2. At which institution are you enrolled? Illinois State University University of Illinois (Urbana - Champaign)

3. Do you identify yourself as a Black/African American?

Other reason backing your ethnic/racial identification as Black/African American?

4.Education level: __Freshman ___Sophomore___Junior___Senior

5. Health status: Are you currently ill or in poor health? [ ] Yes [ ] No

6. Illness / problem

7. Marital Status married with children married with no children single with children single with no children

8. Do you believe you have a disability? [ ] Yes [No]

9. If you believe you have a disability, what do you think it is?

10. How long have you had this disability?. (Years/months)

11. How visible is this disability? [ ] Not at all [ ] A little [ ] Moderately [ ] Mostly [ ] Totally 12. Do you feel other people see or notice this disability? [ ] Not at all [ ] A little [ ] Moderately [ ] Mostly [ ] Totally [ ]

13. How much does this disability affect your life? [ ] Hardly at all [ ] Mildly [ ] Moderately [ ] Severely[ ] Profoundly [ ]

Thank you for this information 


\section{APPENDIX B: PERCEIVED STRESS SCALE}

(COHEN, KLAMARCK, MEMMELSTEIN, 1983)

For each question choose from the following alternatives:

0 - never 1 - almost never 2 - sometimes 3 - fairly often 4 - very often

1.In the last month, how often have you been upset because of something that happened unexpectedly?

2.In the last month, how often have you felt that you were unable to control the important things in your life?

3.In the last month, how often have you felt nervous and stressed?

4. In the last month, how often have you felt confident about your ability to handle your personal problems?

5.In the last month, how often have you felt that things were going your way?

6.In the last month, how often have you found that you could not cope with all the things that you had to do?

7.In the last month, how often have you been able to control irritations in your life?

8.In the last month, how often have you felt that you were on top of things?

9.In the last month, how often have you been angered because of things that happened that were outside of your control?

10.In the last month, how often have you felt difficulties were piling up so high that you could not overcome them? 


\title{
APPENDIX C: MINORITY STUDENT STRESS SCALE
}

\author{
(SMEDLEY ET AL., 1993).
}

The following statements are designed to assess your feelings about the campus climate. Please write a number on the line from 0 (does not apply) to 5 (very stressful) to indicate the level of stress you may associate with each of the statements.

1. The university does not have enough professors of my race

2. Few students of my race are in my classes

3. Racist policies and practices of the university

4. The university lacks concern and support for the needs of students of my race

5. Seeing members of my race doing low status jobs and Whites in high status jobs on campus

6. Few courses involve issues relevant to my ethnic group

7. Negative attitudes/treatment of students of my race by faculty

8. White students and faculty expect poor academic performance from students of my race

9. Pressure that what "I" do is representative of my ethnic group's abilities, behavior, etc.

10. Tense relationships between Whites and minorities at the university

11. The university is an unfriendly place

12. Difficulties with having White friends

13. Negative relationships between different ethnic groups at the university

14. The White-oriented campus culture of the university

15. Having to live around mostly White people

16. The lack of unity/supportiveness among members of my race at the university

17. Trying to maintain my ethnic identity while attending the university

18. Having to always be aware of what White people might do

19. Being treated rudely or unfairly because of my race

20. Being discriminated against

21. White people expecting me to be a certain way because of my race (i.e., stereotyping)

22. Others lacking respect for people of my race

23. Having to "prove" my abilities to others (i.e., work twice as hard)

24. People close to me thinking I'm acting "White"

25. Pressures to show loyalty to my race (e.g., giving back to my ethnic group community)

26. Pressures from people of my same race (e.g., how to act, what to believe)

27. Relationships between males and females of my race (e.g., lack of available dating partners)

28. Doubts about my ability to succeed in college

29. Feeling less intelligent or less capable than others

30. My family has very high expectations for my college success

31. My academic background for college being inadequate

32. My family does not understand the pressures of college (e.g., amount of time or quiet needed to study)

33. Being the first in my family to attend a major university 


\section{APPENDIX D: AFRICULTURAL COPING SYSTEMS INVENTORY}

(UTSEY, ADAMS, AND BOLDEN, 2000).

Recall a stressful situation that occurred within the past week.

Please indicate which coping strategies you used to deal with the stressful situation.

1. Prayed that things would work themselves out.

2. Got a group of family or friends together to help with the problem.

3. Shared your feelings with a friend or family member.

4. Remembered what a parent (or other relative) once said about dealing with these kinds of situations.

5. Tried to forget about the situation.

6. Went to church (or other religious meeting) to get help from the group.

7. Thought of all the struggles Black people have had to endure, which gave you strength to deal with the situation.

8. To keep from thinking about the situation, you found other things to keep you busy.

9. Sought advice about how to handle the situation from an older person in your family or community.

10. Read a scripture from the Bible (or similar book) for comfort and/or guidance.

11. Asked for suggestions on how to deal with the situation during a meeting of your organization or club.

12. Tried to convince yourself that it was not that bad.

13. Asked someone to pray for you.

14. Spent more time than usual doing group activities.

15. Hoped that things would get better with time.

16. Read passage from a daily meditation book.

17. Spent more time than usual doing things with friends and family.

18. Tried to remove yourself from the situation.

19. Sought out people you thought would make you laugh.

20. Got dressed up in my best clothing.

21. Asked for blessings from a spiritual or religious person.

22. Helped others with their problems.

23. Lit a candle for strength or guidance in dealing with the problem.

24. Sought emotional support from family and friends.

25. Burned incense for strength or guidance in dealing with the problem.

26. Attended a social event (dance, party, movie) to reduce stress caused by the situation.

27. Sung a song to yourself to help reduce the stress.

28. Used a cross or other object for its special powers in dealing with the problem.

29. Found yourself watching more comedy shows on television.

30. Left matters in God's hands. 


\section{APPENDIX E: DISABILITY RELATED STRESS SCALE}

(RHODE, FROEHLICH-GROBE, HOCKEMEYER, CARLSON \& LEE, 2012):

Disability Impact: Finances, Interpersonal Relationship, Service Needs (9 items)

-Was a burden to my friends.

-Did not have enough money to cover basic living expenses (e.g., rent, utilities, telephone, food) -Had to rely on others for financial assistance

-Needed to follow up with social service programs

-Did not have enough money for enjoyable activities (e.g., going out to eat, movies, travel)

-Was not able to participate in enjoyable social activities because of my disability

-Had to limit activities due to medical treatment

-Was a burden to my family

-Chose not to participate in enjoyable activities because of my disability

Societal Barriers: Others’ Attitudes (7 items)

-Was treated rudely by another person

-Was not treated with respect

-Was spoken down to by another person

-Dealt with social service program employees who were difficult to talk with

-Was dismissed by another person

-Had difficulty meeting or following social service program rules or requirements (e.g., had to "jump through hoops")

-Was treated differently because of my disability

Participation Limitations: Physical Function and Access to Environment and Technology (11 items)

-Had difficulty getting into public buildings

-Had problems with bowel or bladder functioning

-Had difficulty accessing public restrooms

-Had to wait to do things or get things that non-disabled people don't typically have to wait for -Had difficulty accessing "things" within buildings (e.g., stores, restaurants, movie theater, etc.)

-Had to plan ahead in ways non-disabled people don't typically have to

-Had difficulty using streets, sidewalks, and paths

-Was kept from participating in activities because of personal or medical regimens (e.g., bowel and bladder)

-Had problems with assistive devices not working or working correctly (e.g., pressure relief cushions, crutches)

-Had to adjust activities or plans to be able to participate

-Had difficulty accessing appropriate parking 
Medical Care and Transportation Barriers (10 items)

-Had problems obtaining medical supplies (e.g., catheters)

-Did not have safe transportation

-Could not afford medical supplies (e.g., catheters)

-Did not have affordable transportation

-Had difficulty getting in and around my health care provider's office

-Had problems sticking to medical regimens and/or treatment

-Did not have enough money or health care coverage for needed medical supplies

-Had problems talking with health care provider(s)

-Had difficulty recovering from medical treatment(s)

-Had difficulty scheduling health care appointments.

Accommodation Barriers and Interpersonal Impact (9 items)

-Had problems getting assistive devices (e.g., wheelchairs, pressure relief cushions, crutches)

-Did not have enough money for assistive devices (e.g., wheelchairs, pressure relief cushions, crutches)

-Did not have enough money for home adaptations (e.g., ramps, railings, grab bars, etc.)

-Was required to give up assets to meet eligibility requirements for programs

-Did not have enough money to acquire service animals

-Experienced loss of a friendship as a result of my disability

-Was worried or concerned about changes in my health or functioning

-Did not have enough money for specially adapted clothing (e.g., shoes, pants, etc)

-Had difficulty developing and/or maintaining friendship(s) as a result of my disability

Employment and Social Service Barriers (6 items)

-Had difficulty understanding how employment may affect benefits eligibility

-Had problem(s) finding employment

-Had problems keeping up with changes being made to social service programs

-Had problem(s) getting needed education or training

-Had difficulty finding out about the eligibility requirements for specific social service programs

-Had problems with the application process for social service programs 


\section{APPENDIX F: WORLD HEALTH ORGANIZATION DISABILITY ASSESSMENT}

\section{SCHEDULE 2.0}

\section{(36-ITEM VERSION, SELF-ADMINISTERED, WHODAS II, 2001)}

This questionnaire asks about difficulties due to health conditions. Health conditions include diseases or illnesses, other health problems that may be short or long lasting, injuries, mental or emotional problems, and problems with alcohol or drugs.

Think back over the past 30 days and answer these questions, thinking about how much difficulty you had doing the following activities. For each question, please circle only one response. None Mild Moderate Severe Extreme or Cannot do.

In the past 30 days, how much difficulty did you have in:

Understanding and Communicating

D1.1 Concentrating on doing something for ten minutes?

D1.2 Remembering to do important things?

D1.3 Analyzing and finding solutions to problems in day-to-day life?

D1.4 Learning a new task, for example, learning how to get to a new place?

D1.5 Generally understanding what people say?

D1.6 Starting and maintaining a conversation?

Getting Around

D2.1 Standing for long periods such as 30 minutes?

D2.2 Standing up from sitting down?

D2.3 Moving around inside your home?

D2.4 Getting out of your home?

D2.5 Walking a long distance such as a kilometer [or equivalent]?

\section{Self-Care}

D3.1 Washing your whole body?

D3.2 Getting dressed?

D3.3 Eating?

D3.4 Staying by yourself for a few days?

Getting Along with People

D4.1 Dealing with people you do not know?

D4.2 Maintaining a friendship?

D4.3 Getting along with people who are close to you?

D4.4 Making new friends?

D4.5 Sexual activities? 


\section{Life Activities}

D5.1 Taking care of your household responsibilities?

D5.2 Doing most important household tasks well?

D5.3 Getting all the household work done that you needed to do?

D5.4 Getting your household work done as quickly as needed?

If you work (paid, non-paid, self-employed) or go to school, complete questions D5.5-D5.8, below. Otherwise, skip to D6.1.

Because of your health condition, in the past 30 days, how much difficulty did you have in:

D5.5 Your day-to-day work/school?

D5.6 Doing your most important work/school tasks well?

D5.7 Getting all the work done that you need to do?

D5.8 Getting your work done as quickly as needed?

\section{Participation in Society}

D6.1 How much of a problem did you have in joining in community activities

(for example, festivities, religious or other activities) in the same way as anyone else can?

D6.2 How much of a problem did you have because of barriers or hindrances in the world around you?

D6.3 How much of a problem did you have living with dignity because of the attitudes and actions of others?

D6.4 How much time did you spend on your health condition or its consequences?

D6.5 How much have you been emotionally affected by your health condition?

D6.6 How much has your health been a drain on the financial resources of you or your family?

D6.7 How much of a problem did your family have because of your health problems?

D6.8 How much of a problem did you have in doing things by yourself for relaxation or pleasure?

H1 Overall, in the past 30 days, how many days were these difficulties present?

Record number of days

H2 In the past 30 days, for how many days, were you totally unable to carry out your usual

activities or work because of any health condition?

Record number of days

H3 In the past 30 days, not counting the days that you were totally unable, for how many days

did you cut back or reduce your usual activities or work because of any health condition?

Record number of days

This completes the questionnaire. Thank you 